\title{
POTESTADES PÚBLICAS Y ÁMBITO PRIVADO EN EL SECTOR ELÉCTRICO CHILENO: EL CASO DE LOS CDEC COMO ORGANISMOS AUTORREGULADORES
}

\author{
LEGAL POWERS AND PRIVATE SPHERE IN THE CHILEAN ELECTRIC \\ POWER SECTOR: THE CASE OF THE “CDEC” AS SELF-REGULATORY \\ BODIES
}

\author{
Juan Carlos Ferrada B.* \\ JaVIER TAPIA C. ${ }^{* *}$
}

\begin{abstract}
RESUMEN: Tomando como caso de estudio los llamados "Centros de Despacho Económico de Carga” (o CDEC), encargados de coordinar la operación de cada uno de los dos sistemas eléctricos interconectados existentes en Chile, mostramos que el modelo nacional en esta área está basado en una forma de autorregulación. Los CDEC tienen ciertas potestades regulatorias que determinan la actividad de los agentes del sector, imponiendo obligaciones que condicionan su actividad, las cuales, empero, son supervisadas y ratificadas por uno de los organismos reguladores sectoriales, la Comisión Nacional de Energía (“CNE”). Esto genera una difícil relación jurídica entre ambos entes, lo que manifiesta una aparente tensión entre el rol regulador del Estado y la autorregulación que impulsa el mismo ordenamiento jurídico eléctrico en este caso. Para ilustrar esto, analizamos en detalle las potestades regulatorias de los CDEC en el contexto normativo chileno, su vinculación con las atribuciones dispuestas en este para otros órganos administrativos sectoriales (particularmente la CNE), y el impacto que ello tiene en el diseño del modelo institucional regulatorio eléctrico. Nuestro objetivo no solo es mostrar cómo ha funcionado la autorregulación en la industria eléctrica, sino también ilustrar la serie de dificultades asociadas a la coordinación y a la toma de decisiones en esta materia. Finalizamos el trabajo destacando la necesidad de un cambio institucional que dote al sistema de una mejor estructura orgánica.
\end{abstract}

Palabras clave: sistema eléctrico, CDEC, autorregulación, potestades, coordinación

ABSTRACT: The so-called Centros de Despacho Económico de Carga (o "CDEC") are the system operators in each of the two interconnected Chilean electric power systems. Taking them as case study, we demonstrate that the national model is based upon a form of selfregulation. The CDEC have some legal regulatory powers that allow them to influence the activity of the firms by imposing requirements. Such powers are under the supervision and/or confirmation of one of the sector specific regulatory bodies, the Comision Nacional de Energia ("CNE"). This produces a difficult relation between the CDEC and the CNE, which seems to manifest an apparent tension between the regulatory role of the State and the self-regulation that inspires the legal framework in this area. To elucidate the point, we

\footnotetext{
Doctor en Derecho, Universidad Carlos III de Madrid (España); Profesor de Derecho Administrativo, Universidad de Valparaíso, e-mail: juancarlos.ferrada@uv.cl.

** Doctor en Derecho, University College London (Reino Unido); Académico, Universidad de Chile; senior research fellow, Centre for Law, Economics \& Society, UCL (Reino Unido); Director de Asuntos Jurídicos, Asociación Gremial de Generadoras de Chile, e-mail: jtapia02@gmail.com. Las opiniones vertidas en este trabajo son personales y no necesariamente representan las de la Asociación o sus asociados.
} 
analyse in detail the legal powers the CDEC have under Chilean law; consider their relation with the powers of sector specific regulators (especially the CNE); and show the impact for institutional design in the electric power sector in Chile. The aim is not only showing how the self-regulatory model has worked in practice. It is also to illustrate the number of difficulties arising from coordination and the decision-making process in this area. Finally, we highlight the need for an institutional change to improve the system organically.

Key words: electric power system, CDEC, self-regulation, legal powers, coordination

\section{INTRODUCCIÓN}

Históricamente, la pregunta general por el modelo de regulación subyacente al sector eléctrico, o el que resulta más adecuado y provee una mejor "gobernanza” para este, atendidas sus características y los objetivos que persigue, ha estado ausente de los debates y -quizás más relevante aún- de los graduales cambios normativos que se han introducido en la institucionalidad chilena en esta materia. Por el contrario, los avances se han caracterizado por responder (con un mayor o menor grado de éxito) a meros eventos coyunturales, ser una consecuencia de la insatisfacción de los actores relevantes del sector, o configurar una solución normativa episódica y no articulada vinculada a intereses políticos contingentes. En general, es posible afirmar que en este sector ha existido una ausencia de un enfoque de largo plazo y de una mirada sistémica e interdisciplinaria al tema del diseño institucional ${ }^{1}$. Este trabajo es un esfuerzo por comenzar a llenar este vacío.

Tomando como caso de estudio los llamados "Centros de Despacho Económico de Carga” (o CDEC), encargados de coordinar la operación de cada uno de los dos sistemas eléctricos interconectados existentes en Chile, mostramos que el modelo nacional está basado en una forma de autorregulación. Se trata, quizás, de un caso único en el mundo, pues por regla general la operación de los sistemas eléctricos no suele estar entregada a un conjunto de privados, sino a una entidad o empresa en particular o a algún ente en el cual el Estado posee algún grado de injerencia ${ }^{2}$. El caso chileno permite mostrar no solo cómo ha funcionado la autorregulación en la industria eléctrica, sino también ilustrar la serie de dificultades asociadas a la coordinación y a la toma de decisiones en esta materia.

\footnotetext{
${ }^{1}$ La literatura nacional y comparada acerca del proceso chileno suele centrarse en evaluaciones económicas del período postprivatización. Véase, por ejemplo, Serra (2002), Soto et al. (1996), Estache y Rodríguez-Pardina (2000); Pollitt (2004). Solo de manera reciente, en el año 2011, la Comisión Asesora para el Desarrollo Eléctrico (CADE) adoptó una visión diferente, pero su composición no interdisciplinaria dio lugar a críticas por sobre lo razonable de sus posturas (CADE 2011).

2 Dentro del primer caso se encuentra, por ejemplo, el Reino Unido, donde la operación del mercado está actualmente entregada a National Grid, el principal transmisor. De modo similar, en Colombia la operación corresponde a la Compañía de Expertos en Mercado (XM), la cual es una filial del transmisor ISA. Ejemplos del segundo caso son Argentina, donde la operación del mercado está entregada al CAMMESA, en el cual participa en su capital accionario el Estado a través del Ministerio de Planificación Federal Inversión Pública y Servicios; y la República Dominicana, donde el organismo coordinador del sistema eléctrico interconectado está a cargo del "Consejo de Coordinación", el cual está compuesto por cuatro bloques que agrupan a los agentes del mercado y que está presidido por un representante del Superintendente de Electricidad. Estas no son las únicas alternativas. Para un análisis general, véase Rudnick y Alvarez (2001).
} 
Como mostraremos, la situación institucional de los CDEC puede ser caracterizada como lo que la doctrina conoce como "corregulación"”. Se trata de organismos que tienen ciertas potestades regulatorias que determinan la actividad de los agentes del sector, imponiendo obligaciones que condicionan su actividad, las cuales, empero, son supervisadas y ratificadas por uno de los organismos reguladores sectoriales, la Comisión Nacional de Energía ("CNE”). Esto genera una difícil relación jurídica entre ambos entes, lo que manifiesta una cierta tensión que pareciera existir entre el rol regulador del Estado y la autorregulación que impulsa el mismo ordenamiento jurídico eléctrico en este caso. Para ilustrar esto, analizamos en detalle las potestades regulatorias de los CDEC en el contexto normativo chileno, su vinculación con las atribuciones dispuestas en este para otros órganos administrativos sectoriales (particularmente la CNE), y el impacto que ello tiene en el diseño del modelo institucional regulatorio eléctrico.

El resto del trabajo se estructura en cinco apartados principales. En el primero exponemos el marco teórico, mostrando la aparente dicotomía entre regulación y autorregulación y caracterizando las diversas formas que esta última puede asumir. A continuación, revisamos los rasgos centrales de la configuración institucional del sector bajo la Ley General de Servicios Eléctricos ("LGSE") ${ }^{4}$. En tercer término, analizamos la institucionalidad regulatoria del sector eléctrico, identificando el rol que le corresponde a los órganos regulatorios estatales dentro de aquella, sobre todo a partir de la reforma introducida en el sector por la Ley $\mathrm{N}^{\circ} 20.402$ de 2009. En cuarto lugar, estudiamos a los CDEC dentro del sistema regulatorio eléctrico, identificando sus características principales dentro de este. Por último, abordaremos el modelo de corregulación del sistema eléctrico chileno, poniendo en relación las potestades de supervisión regulatoria que ejerce la CNE y las atribuciones otorgadas a los CDEC en esta misma materia. Luego del análisis, presentamos algunas conclusiones y propuestas para el desarrollo institucional a futuro en este ámbito.

\section{MÁS ALLÁ DE LA “REGULACIÓN" Y LA “AUTORREGULACIÓN"}

En términos generales, la "autorregulación” tiene lugar cuando un grupo de individuos o firmas ejerce control sobre su propia membresía y/o su comportamiento 5 . Tradicionalmente, este último concepto es entendido de manera restrictiva, como opuesto a la regulación más intrusiva de "comando y control"'. Sin embargo, si bien esta dicotomía puede ser un buen punto de partida analítico, ella es insuficiente para capturar el amplio rango de opciones que están entre la discreción absoluta de los particulares y el control estatal total'. En este contexto, que puede ser visto como un continuum entre los dos extremos mencio-

\footnotetext{
3 Véase infra, sección 5.3.

4 Decreto con Fuerza de Ley $N^{\circ}$ 4/20.018 que fija el texto refundido, coordinado y sistematizado del Decreto con Fuerza de Ley $N^{\circ}$ 1, del Ministerio de Minería, de 1982, Ley General de Servicios Eléctricos en materia de Energía Eléctrica.

5 La literatura sobre el tema es vasta. A nivel internacional, véase, por ejemplo, Coglianese \& Mendelson (2010), Parker (2002) y Black (1997). En Chile, véase, a modo ejemplar, Núñez (2002).

6 En la literatura regulatoria, véase, por ejemplo, SpUlber (1989).

7 Véase, Baldwin, Cave y Lodge (2012: esp. cap. 8); Sinclair (1997) y Black (2001).
} 
nados, la noción de "autorregulación" necesariamente implica mucho más que la simple libertad de los privados para proveerse de sus propias normas. Como expresa un autor, "la regulación no-gubernamental viene en variados disfraces"8.

En efecto, la literatura regulatoria ha reconocido una serie de alternativas a la autorregulación puramente privada, incorporando en todas ellas la participación estatal. Entre los principales ejemplos están la "corregulación", que implica la regulación privada con algún nivel de supervisión o ratificación gubernamental"; y la "autorregulación forzada" (enforced self-regulation), que involucra una suerte de "negociación” entre el Estado y firmas individuales para establecer regulaciones particularizadas para cada una de ellas ${ }^{10}$. Estas y otras alternativas tienen en común el hecho que permiten plasmar de mejor manera que la regulación directa (de "comando y control"), objetivos tales como experticia, eficiencia, accountability, adaptabilidad y legitimidad.

En la práctica, entonces, la buena gobernanza regulatoria requiere aparentemente de una mirada más amplia, pública y privada. En la actualidad casi la totalidad de los sistemas regulatorios mezclan al menos algún elemento de autorregulación y alguno de supervisión o influencia estatal. Lo crucial es utilizar el "mix regulatorio" que sirva mejor a los objetivos buscados y a la legitimación del sistema ${ }^{11}$.

Como mostraremos en los apartados siguientes, nuestro sistema eléctrico incorpora elementos de regulación no estatal con ratificación estatal. Si bien este no fue el resultado de un diseño deliberado, su desarrollo ha sido consistente con un sistema que incorpora un nivel apropiado de "check and balances", lo que permite afirmar que -en términos generalessu mantención, profundización y perfeccionamiento continuo siguen siendo recomendables.

\section{ALGUNOS ANTECEDENTES RELEVANTES DEL SECTOR ELÉCTRICO CHILENO}

\section{A. DOS PILARES DEL SISTEMA: PRIVATIZACIÓN Y LIBERALIZACIÓN}

La reforma estructural y regulatoria implementada a principios de los años 80 en el sector eléctrico chileno estuvo fundamentalmente dirigida a la consecución de dos objetivos: atraer inversiones privadas al sector y crear un régimen basado esencialmente en la competencia en el mercado ${ }^{12}$. El primero fue materializado a través de una creciente y progresiva privatización de las empresas que participaban en el sector. Las dos empresas que hasta antes de la reforma eran responsables por más del $80 \%$ de la generación, transmisión y distribución en el país (Endesa y Chilectra) fueron divididas en varias unidades, para

\footnotetext{
8 BaLleisen (2010: 446).

9 La formulación original corresponde a Grabosky y BraithWAITE (1986: 83).

10 Ayres \& Braithwaite (1992: cap. 4).

11 "El problema usualmente no es la autorregulación per se, sino la falla en integrar estructuras de gobernanza privada de manera efectiva dentro de un marco institucional más completo - incorporar esas estructuras dentro de un marco de supervisión pública más amplio" (BALleisen \& Eisner, 2009: 129 [traducción de los autores]).

12 A estos dos objetivos se uniría, un par de décadas más tarde, el objetivo instrumental y secundario (en el sentido que su justificación es permitir la competencia) de proveer acceso abierto, alcanzado a través de la desintegración vertical de las firmas de transmisión y generación.
} 
posteriormente ser transferidas a manos privadas, fundamentalmente entre los años 1986 y 1989, una vez que el sector había sido reestructurado ${ }^{13}$.

El segundo objetivo ya enunciado fue la "creación" de mercados donde ello fuera posible, salvo en aquellos ámbitos en los que el negocio revistiera características de monopolio natural ${ }^{14}$. Este objetivo estuvo fundado en la creencia-crecientemente dominante en ese entonces- según la cual el Estado, con sus controles supuestamente indeseables y sus interferencias generalizadas, debía retroceder, cediéndole casi por completo los espacios a la iniciativa privada ${ }^{15}$. Tal creencia reflejaba una verdadera confianza en un razonamiento determinístico, según el cual el mercado sería capaz de producir el máximo bienestar posible para los individuos en una sociedad. Esto significó que los supuestos tradicionales tenían un sesgo cognitivo hacia el mercado como benchmark, por cuanto este es el adjudicador más eficiente; siendo la eficiencia, por cierto, el objetivo prominente a ser buscado.

Este objetivo de creación de mercados fue alcanzado a través de la liberalización del segmento generación, el único donde se estimó posible introducir competencia (considerada, a su vez, el mejor mecanismo para alcanzar dicho objetivo), sumado al diseño del sistema de precios bajo un esquema casi completamente desregulado ${ }^{16}$. En contraste, los segmentos que presentan características de monopolio natural en su provisión (esto es, la transmisión y distribución eléctrica) fueron sometidos a regulación de precios y dotados del carácter de servicio público ${ }^{17}$. Si bien este diseño respondió primordialmente a objetivos técnicos, económicos y políticos, a partir de él surge una pregunta jurídica fundamental que impacta la operación del sistema: cómo administrar la interrelación permanente que se genera entre actividades altamente reguladas y otras sujetas a un menor (o casi nulo) nivel de regulación. La respuesta demandaba una solución jurídica tanto o más sólida que

13 El Estado culminaría el gradual proceso de enajenación de su participación en las empresas eléctricas en 1999, con la venta de su participación remanente en Edelnor. En la actualidad el 100\% de la propiedad de las empresas está en manos privadas. Para mayores antecedentes del proceso, véase FISHER y SERRA (2007).

14 Alé (1990) p. 188.

15 Las críticas a este aspecto del modelo están fuera de los límites autoimpuestos en este trabajo. Baste mencionar que la literatura más reciente aboga al menos por una profunda revisión de este enfoque, comenzando por reconocer que la "retirada" del Estado nunca ha sido tal, sino que lo único que se ha percibido es una reconfiguración de las fronteras entre este y los mercados, con el consiguiente "reacomodo" de la participación del gobierno y los privados en la economía (véase, por ejemplo, Vogel 1996 y Braithwaite 2008). Por una parte, esto trae como consecuencia la necesidad de considerar todas las características de la industria para escoger el diseño más adecuado entre un gran número de alternativas, que van mucho más allá de la falsa y caricaturesca dicotomía mercado vs. Estado o laissez-faire vs. planificación. Por otra parte, trae aparejado un reconocimiento de que los objetivos sustantivos de la regulación son heterogéneos (no necesariamente se debe privilegiar la eficiencia) y que existen múltiples e importantes formas de resolver los trade-offs entre esos objetivos (más allá de la preeminencia de la competencia).

16 La desregulación (parcial) de precios en el segmento liberalizado fue complementada con una regulación de precios y de calidad de servicio en el segmento monopólico de la distribución. Asimismo, el sistema fue diseñado principalmente sobre la base de la aplicación del modelo marginalista, de modo que la operación al mínimo costo quedara equiparada en términos de importancia a la seguridad de suministro. Véase Alé (1990: 187 y ss.).

17 El artículo $8^{\circ}$ de la LGSE indica expresamente que "No se considerarán servicio público los suministros efectuados desde instalaciones de generación, la distribución de energía que hagan las Cooperativas, no concesionarias, o bien la distribución que se realice sin concesión". 
las técnica y económica. Sin embargo, la primera fue (y continúa siendo) sistemáticamente relegada en favor de las segundas ${ }^{18}$.

Como consecuencia de la privatización del mercado eléctrico y de la liberalización/desregulación del segmento generación, en el sistema chileno las decisiones de inversión, producción y comercialización son adoptadas exclusivamente por agentes privados, sujetos siempre al marco regulatorio general que rige su actividad y a las obligaciones que de él emanan ${ }^{19}$.

\section{B. LA OPERACIÓN DEL SISTEMA}

La interrelación que se produce entre producción y consumo de electricidad es instantánea, y está determinada por la imposibilidad de almacenamiento de la energía eléctrica. Es decir, existe una exigencia de carácter físico de acuerdo a la cual en todo momento la oferta de electricidad debe igualar a la demanda por ese mismo producto ${ }^{20}$. En un modelo como el chileno, que combina un segmento competitivo y uno monopólico, esto conlleva a la necesidad factual de actuar en sincronismo, de modo que siempre un cliente (libre o regulado) pueda proveerse de energía por parte de cualquiera de los generadores competidores.

Esta necesidad física fue plasmada en la normativa a través de una obligación de iure de interconectar las instalaciones eléctricas y actuar de manera coordinada con el objeto de actuar en provecho del conjunto, preservando la seguridad del suministro eléctrico y garantizando la operación más económica del sistema con independencia de la propiedad de las instalaciones ${ }^{21}$.

En sus comienzos, el diseño institucional no se hizo cargo a nivel legal de los detalles de estas obligaciones, sino que solo encargó que ellas se cumplieran, "de acuerdo a las

\footnotetext{
18 Por esto, los controles al poder de mercado en el segmento desregulado contrastan con los escasos avances en la regulación de los sectores sujetos a una obligación de servicio público. La creencia de que regulación de precios (por incentivos) era suficiente ha frenado avances en importantes aspectos que requieren cambios estructurales urgentes, entre los cuales están, por ejemplo, evitar el crecimiento progresivo del monopolio natural, incentivar la innovación, analizar los fundamentos de su rentabilidad, y avanzar en la desintegración introduciendo competencia en retail (comercialización), entre otros.

19 Este principio, establecido desde los inicios de la LGSE en 1982, no ha cambiado a pesar de las sucesivas modificaciones a que ha sido sometida. En este sentido, por ejemplo, VERGARA (2001) p. 6, ha indicado que "la inspiración y sistema establecido en la primigenia LGSE de 1982 se ha mantenido, con complementos y ajustes, pero básicamente manteniendo el texto original. // De ahí que consideramos al D.F.L. $\mathrm{N}^{\circ} 4$ como un texto que sistematiza formalmente la LGSE de 1982 (D.F.L. $\mathrm{N}^{\circ}$ 1) con sus modificaciones, ajustes y mejoras; pero no constituye el D.F.L. N 4 una Ley sustitutiva y radicalmente nueva; pues en cuanto a la sustancia se mantiene la inspiración y sistema instaurado en 1982" (énfasis en el original).

20 En otras palabras, una característica física de la energía constriñe la operación del mercado eléctrico y hace que la operación deba ser insoslayablemente de "suma cero", de modo de asegurar que el total de la energía que se produce sea instantáneamente consumida.

21 El artículo $81^{\circ}$ del texto original de la LGSE, actual $137^{\circ}$, indicaba en su parte pertinente que: "Los concesionarios de cualquier naturaleza están obligados a llevar a cabo la interconexión de sus instalaciones cuando con informe de la Comisión se determine mediante decreto supremo del Ministerio del Interior. // La operación de las instalaciones eléctricas de los concesionarios que operen interconectados entre sí, deberá coordinarse con el fin de: 1.- Preservar la seguridad del servicio en el sistema eléctrico; 2.- Garantizar la operación más económica para el conjunto de las instalaciones del sistema eléctrico; 3.- Garantizar el derecho de servidumbre sobre los sistemas de transmisión establecidos mediante concesión. // Esta coordinación deberá efectuarse de acuerdo con las normas y reglamentos que proponga la Comisión. [...]”.
} 
normas y procedimientos que proponga [el regulador]"22. En la práctica, lo único que se produjo fue una suerte de "acomodo" de la operación a la nueva realidad privada del sistema y a los principios rectores dispuestos en la LGSE. Dado que los generadores existentes, principalmente Endesa, tenían un mejor conocimiento práctico de la dimensión operativa, se les confió a ellos la tarea de actuar como "guía" de las decisiones de operación ${ }^{23}$ y transmisión (segmento que en ese entonces estaba verticalmente integrado con Endesa ${ }^{24}$ ). Con esto, el modelo mantuvo fundamentalmente la situación vigente de forma previa a la privatización, sin que existiera, en cambio, un diseño institucional premeditado y específico de operación del sistema.

A partir del año 1985, las obligaciones de interconexión y coordinación pasaron a canalizarse formalmente a través de los llamados "Centros de Despacho Económico de Carga" (“CDEC") ${ }^{25}$, situación que se mantiene hasta el día de hoy y que más adelante analizamos con mayor detalle ${ }^{26}$.

\section{LA INSTITUCIONALIDAD REGULATORIA EN EL SISTEMA ELÉCTRICO CHILENO}

\subsection{El Diseño instituCiOnAL ORiginal}

En Chile, el diseño regulatorio estatal original postprivatización estaba basado en una triple división de funciones entre un Ministerio (originalmente el Ministerio del Interior, luego reemplazado por el de Economía, Fomento y Reconstrucción o "MinEcon”), la Superintendencia de Electricidad y Combustibles ("SEC") y la CNE, siendo esta última el eje central de la función reguladora ${ }^{27}$.

La CNE fue creada en el año 1978, con la dictación del Decreto Ley $\mathrm{N}^{\circ} 2224$, el cual, en cierta medida, fue un "adelanto" del proceso de privatización que se iniciaría pos-

22 Artículo $81^{\circ}$ del texto original de la LGSE. Nótese que el texto original de la ley no establecía la obligación de coordinarse "a través de un CDEC", como indica el texto actual. Al respecto, compárese el original artículo $81^{\circ}$ de la LGSE con el actual artículo $137^{\circ}$. Los dos objetivos mencionados en el texto principal permanecen inalterados.

23 Entre dichas tareas se encontraba, por ejemplo, el programa de generación y de transferencias. Como señalan PAREDES y SAPAG (2001) p. 17: "Hasta fines de 1978, la regulación del sector se efectuaba parcialmente bajo la responsabilidad de Endesa, por ser esta la empresa de mayor capacidad técnica, lo que la dejaba en condiciones de poder establecer las normas de operación, los estándares de calidad de servicio y las propuestas tarifarias". En términos similares, véase FISHER y SERRA (2007).

24 El marco normativo original distinguía entre las actividades de generación, transmisión y distribución, pero no prohibía la integración vertical de estas.

25 Artículos $137^{\circ}$, inciso final, y $138^{\circ}$ de la LGSE. Como explica un autor, "La coordinación de la maquinaria eléctrica para suministrar energía, que podemos llamar coordinación física, se sustenta en un diseño de ingeniería; la coordinación de los intercambios de productos y servicios se sustenta en un modelo económico. En el caso chileno, ambas coordinaciones se han concentrado en una misma entidad..." (SEPÚlVEdA, 2010: 68). Los CDEC son actualmente dos en nuestro ordenamiento, uno por cada sistema interconectado.

26 Véase infra, sección 4.2.

27 Como veremos en la sección siguiente, este esquema se mantuvo sin alteraciones hasta el año 2009. 
teriormente $^{28}$. La CNE, cuya dirección superior estaba a cargo de un Consejo Directivo ${ }^{29}$ y de un Secretario Ejecutivo, como jefe superior del servicio, fue desde un principio concebida como el organismo regulador por excelencia en el sector. Se trataba de un servicio descentralizado encargado de "elaborar y coordinar los planes, políticas y normas" para su "buen funcionamiento" 30 . Para estos efectos, se le dotaba de las más amplias facultades, entre las cuales se incluía un número importante de atribuciones que hoy han pasado a manos del Ministerio de Energía, tales como la elaboración de planes de desarrollo del sector, el estudio de proyecciones de oferta y demanda del sector, y la elaboración de normas, entre otras $^{31}$.

Como se observa, las competencias de la CNE excedían el ámbito estrictamente técnico y entraban derechamente en el campo de las políticas públicas sectoriales. En efecto, al MinEcon solo le fueron entregadas facultades formales de dictación de los decretos tarifarios y otorgamiento de concesiones definitivas, careciendo de un rol planificador o programático. Es decir, era la CNE quien tenía a su cargo todos los elementos estratégicos de desarrollo del sector energético en Chile.

En el año 1985 se dicta la Ley $N^{\circ} 18.410$, que crea la SEC, a la cual, como servicio descentralizado, le corresponde "fiscalizar y supervigilar el cumplimiento de las disposiciones legales y reglamentarias, y normas técnicas sobre generación, producción, almacenamiento, transporte y distribución de combustibles líquidos, gas y electricidad, para verificar que la calidad de los servicios que se presten a los usuarios sea la señalada en dichas disposiciones y normas técnicas, y que las antes citadas operaciones y el uso de los recursos energéticos no constituyan un peligro para las personas o cosas"32.

Este modelo regulatorio institucional del sector energético, concebido desde los inicios de la reforma, se mantuvo prácticamente sin variaciones por casi tres décadas. Sin embargo, de manera creciente comenzó a ser visto negativamente por los distintos actores públicos y privados relacionados con el área. Se estimaba que no existía una mirada integral al tema de la energía en nuestro ordenamiento, lo que era consecuencia principalmente de la diversidad de organismos y dependencias del aparato público responsable en la materia. Aún más, se estimaba que el órgano público con mayor responsabilidad en esta temática, la CNE, no tenía el rango, ni las potestades suficientes para coordinar el sector energético, focalizándose la mayoría de las atribuciones relevantes en el Ministerio Economía, órgano

\footnotetext{
28 De hecho, la propia LGSE fue redactada por la CNE.

${ }_{29}$ El Consejo Directivo estaba conformado por un representante del Presidente de la República, quien lo presidía, y por seis ministros (artículo $5^{\circ}$ original del DL $N^{\circ} 2.224 / 78$ ). En buena medida, este consejo fue el continuador de la "Comisión de Tarifas", dependiente del Ministerio del Interior, que calculaba las tarifas en el sector desde la dictación del DFL N 4 de 1959. A partir de la dictación de la Ley $\mathrm{N}^{\circ} 16.464$, de 1966, toda alza debía quedar sujeta a la aprobación del MinEcon.

30 Artículo $2^{\circ}$ original del DL 2.224/78. Compárese con el actual artículo $6^{\circ}$ (infra, nota 40 y el texto principal al que acompaña).

31 Véase artículo $4^{\circ}$ original del DL 2.224/78.

32 Artículo 2 de la Ley $N^{\circ}$ 18.410. Los antecedentes orgánicos de la SEC se remontan a 1904, cuando se crea la "Inspección Técnica de Empresas y Servicios Eléctricos", que luego pasaría a llamarse "Superintendencia de Electricidad" y finalmente "Superintendencia de Electricidad y Combustibles con la Ley N 18.410.
} 
que tenía otras prioridades y objetivos en el diseño e impulso de las políticas públicas ${ }^{33}$. Como veremos a continuación, esto propició cambios fundamentales en el diseño, que redundan en la forma de supervisión regulatoria.

\subsection{El REDiseño instituCiOnAL EN EL AÑo 2009 y SU HOMOlOGACión CON EL} SISTEMA ADMINISTRATIVO GENERAL

A fines del año 2009, el legislador dictó la Ley N² 20.402, que creó el Ministerio de Energía, modificó la CNE y rediseñó parcialmente (pero de manera crucial) la institucionalidad pública competente en este sector. Esta nueva regulación entró en vigencia en febrero de 2010, luego que se dictara el Decreto con Fuerza de Ley $N^{\circ}$ 12/2009, del Ministerio de Hacienda ${ }^{34}$.

En este nuevo diseño institucional, el Ministerio de Energía asume claramente -como ocurre en otros ámbitos sectoriales con los departamentos ministeriales- un rol de colaborador directo del Presidente de la República en la dirección política del sector, proponiendo a este las políticas, planes, programas y normas en esta materia ${ }^{35}$. En este sentido, la Ley $\mathrm{N}^{\circ} 20.402$ atribuye exclusivamente a este Ministerio el objetivo general de "[E]laborar y coordinar los planes, políticas y normas para el buen funcionamiento y desarrollo del sector, velar por su cumplimiento y asesorar al Gobierno en todas aquellas materias relacionadas con la energía" 36 .

Al mismo tiempo, la aludida ley suprimió los roles que tenían el MinEcon y la CNE en esta materia. Asimismo, para el cumplimiento de esta misión, la misma ley le asigna al Ministerio de Energía un conjunto de funciones y atribuciones relacionadas con el estudio y proyecciones de la oferta y demanda de energía en nuestro país, la preparación de políticas y planes del sector, la elaboración, dictación y fiscalización de las normas del sector, la fijación de los estándares mínimos de eficiencia energética que deben cumplir los productos y equipos, y otras funciones y tareas que las leyes le encomienden para el desarrollo del sector energético ${ }^{37}$.

De estas atribuciones, una de la más relevantes, para los efectos de este trabajo, es la que habilita al Ministerio para la elaboración, coordinación, propuesta y dictación de las normas aplicables al sector de energía ${ }^{38}$, ya que ella le permite establecer la regulación sectorial necesaria para lograr la eficiencia energética, la seguridad del sistema y el adecuado funcionamiento y desarrollo del sector en su conjunto. Esto implica la asignación al Ministerio de Energía de potestades normativas relevantes, las que obviamente deben enmarcarse

\footnotetext{
33 "Mensaje No 1293-355 de S.E. la Presidenta de la República con el que se inicia un proyecto de ley que crea el Ministerio de Energía, estableciendo modificaciones al DL. № 2.224 de 1978 y a otros cuerpos legales", de 16 de enero de 2008, en Historia de la Ley $N^{\circ}$ 20402, Biblioteca del Congreso Nacional, pp. 7-9.

34 El DFL 12/09 fija la planta de personal de la Subsecretaría de Energía, el régimen de remuneraciones que le será aplicable, y modifica la planta de personal de la CNE, cumpliendo así con lo dispuesto en el artículo $5^{\circ}$ transitorio de la Ley $\mathrm{N}^{\circ} 20.402$.

35 Artículo 22 de la LOCBGAE.

36 Artículo $2^{\circ}$ del DL N².224/78.

37 Artículo $4^{\circ}$ del DL No $2.224 / 78$.

38 Artículo $4^{\circ}$ letra "d" del DL N ${ }^{\circ} 2.224 / 78$.
} 
en el conjunto de las disposiciones establecidas en el ordenamiento jurídico, no pudiendo extenderse a materias ajenas al sector, ni transgredir los derechos reconocidos a los operadores del sistema energético en esta u otras normas jurídicas.

\subsection{El papel de la CNE y la SEC en la nUEVA InSTitucionalidad REgUlatoria}

No obstante las innovaciones introducidas por la Ley $\mathrm{N}^{\circ} 20.402$ ya apuntadas, esta mantuvo a la CNE como un órgano relevante del sector, pero reformulando su papel en esta nueva institucionalidad pública. Así aparecerá más claramente como un organismo técnico asesor, suprimiendo sus funciones directivas y ejecutivas en el sector; especialmente aquellas relacionadas con la elaboración y coordinación de las políticas, planes y programas en este ámbito ${ }^{39}$. De este modo, de acuerdo al nuevo texto del DL No 2.224, la CNE pasa a ser: " $[\mathrm{U}] \mathrm{n}$ organismo técnico encargado de analizar precios, tarifas y normas técnicas a las que deben ceñirse las empresas de producción, generación, transporte y distribución de energía, con el objeto de disponer de un servicio suficiente, seguro y de calidad, compatible con la operación más económica" ${ }^{40}$.

En este marco, la misma ley señala que, sin perjuicio de las demás atribuciones conferidas en otros cuerpos legales, la CNE tiene como funciones y atribuciones principales el análisis técnico de la estructura y nivel de los precios y tarifas de bienes y servicios energéticos, la fijación de las normas técnicas y de calidad indispensables para el funcionamiento y la operación de las instalaciones energéticas y el monitoreo y proyección del funcionamiento actual y esperado del sector energético ${ }^{41}$.

A esto debe añadirse un alto número de funciones y atribuciones señaladas para la CNE en la LGSE ${ }^{42}$ y otras atribuciones generales dispuestas en el Decreto Supremo $N^{\circ} 291 / 2007$ (que aprueba el reglamento que establece la estructura, funcionamiento y

\footnotetext{
39 De hecho, a pesar de conservar el nombre, a la CNE se le quitó el carácter de "comisión", al suprimirse su Consejo Directivo, transformándose así en un organismo unipersonal. Con todo, las facultades directivas superiores que el DL 2.224/78 otorgaba originalmente al Consejo no fueron traspasadas de manera explícita al Secretario Ejecutivo, quien mantiene sus funciones de administración y jefe superior del servicio. Jurídicamente, entonces, la CNE carece de una instancia que la dirija.

40 Artículo $6^{\circ}$ del Decreto Ley $N^{\circ} 2.224 / 78$ (negritas agregadas). Compárese esta naturaleza técnica con la caracterización original de la CNE indicada supra, nota 30 y el texto principal al que acompaña.

41 Artículo $7^{\circ}$ del Decreto Ley $\mathrm{N}^{\circ} 2.224 / 78$.

42 Por ejemplo, las referidas a la aprobación de los pliegos de las normas técnicas que debe dictar la Superintendencia de Electricidad y Combustibles para la aplicación de esta ley (Artículo 10), la opinión o informe para la transferencia de concesión de servicio público de distribución eléctrica o la determinación por la autoridad de las líneas y subestaciones de cada sistema de transmisión troncal (Artículos 47 y 74, respectivamente), la elaboración del cálculo y el informe técnico previo a la resolución que realice el Panel de Expertos en la discrepancia provocada entre las empresas por el valor anual de la transmisión por tramo (Artículos 107 y 108), la confección del informe técnico con las tarifas de subtransmisión y sus respectivas fórmulas de indexación para un período determinado (Artículo 112), la aprobación de las bases para licitaciones de suministro individuales o conjuntas elaboradas por las concesionarias para las distribuidoras (Artículo 132), la elaboración del informe que establezca la interconexión de las empresas concesionarias por decreto ministerial y la proposición de normas y reglamentos que establezcan la coordinación de las empresas generadoras a través de un CDEC (Artículo 137), entre muchas otras.
} 
financiamiento de los CDEC ${ }^{43}$. Estas últimas deben entenderse como una expresión concreta de las habilitaciones genéricas dispuestas en la LGSE de proposición de las normas y reglamentos de coordinación de los CDEC (Artículo 137) y de control y supervisión de estos (Artículo 225 letra "b”), sin que puedan importar potestades específicas para restringir la actividad de los particulares, salvo en los términos generales establecidos en esta Ley y en el DL N².224/78.

A lo anterior debe sumarse el rol que cumple la SEC, como órgano fiscalizador y sancionador del sector, ámbitos que no fueron alterados por la Ley $\mathrm{N}^{\circ} 20.402$, manteniendo la separación material entre órganos políticos, técnicos y administrativos propiamente tales. En este sentido, y según lo dispuesto en la Ley N 18.410, la SEC continúa siendo el órgano administrativo encargado de la fiscalización y supervigilancia del sector energético chileno y, en este marco, la ley le atribuye una amplia variedad de potestades ${ }^{44}$.

\subsection{El IMPACTO DE LA LEY N²0.402 EN LA INSTITUCIONALIDAD REGULATORia ELÉCTRICA}

Como se puede observar, la reforma del año 2009 vino a rediseñar, de manera fundamental, las instituciones y competencias originales de los organismos públicos en el sector. A partir de entonces, este se estructura en torno a un ministerio y algunos servicios públicos que regulan la actividad desarrollada por el sector privado, fijando los objetivos, las políticas, los planes y las normas que debe seguirse en esta materia ${ }^{45}$. Al mismo tiempo, se consolidó el esquema administrativo previstos en la Ley Orgánica Constitucional de Bases Generales de la Administración del Estado (LOCBGAE) ${ }^{46}$.

En este contexto, se puede sostener con claridad que hoy existe en nuestro ordenamiento jurídico un complejo entramado de órganos y potestades que tienen incidencia en el sector eléctrico, estableciéndose una distribución competencial entre estos, atendida la naturaleza de la función asignada y su conexión con los objetivos institucionales que la ley ha puesto bajo su cargo. Así, cada órgano estatal asume un rol específico dentro del sistema institucional, debiendo sus competencias ser interpretadas de manera armónica, de acuerdo a los objetivos atribuidos a cada uno de ellos dentro de dicho sistema.

\footnotetext{
43 Por ejemplo, la "información favorable" de los procedimientos elaborados por las direcciones técnicas del respectivo $\mathrm{CDEC}$, en los que dispongan sus metodologías y mecanismos de trabajo (Artículos 10, 36 letra $\mathrm{k}$ y 37 letra "d"), de los presupuestos de los CDEC (Artículo 66) y de los reglamentos internos de estos (Artículo 25 letra "d"), entre otras. A esta materia nos referimos infra, en sección 5.2.

44 Tales como como la fiscalización de las instalaciones y servicios eléctricos, la adopción transitoria de las medidas necesarias para la seguridad del público y el resguardo del derecho de los concesionarios y consumidores de energía eléctrica, la sanción por el incumplimiento de las normas técnicas y reglamentarias del sector y la aplicación e interpretación administrativa de las disposiciones legales y reglamentarias cuyo cumplimiento le corresponde vigilar, entre otras funciones y atribuciones relevantes.

45 A esto se suman los CDEC y el Panel de Expertos. Los primeros son analizados infra, sección 4.

46 Esto es, con un Ministerio que colabora con el Presidente de la República en la definición de políticas, planes, programas y normas, y con servicios públicos que ejecutan estas políticas y satisfacen necesidades públicas de forma regular y continua (artículos 22 y 28 de la LOCBGAE).
} 


\section{LOS CDEC EN LA INSTITUCIONALIDAD REGULATORIA CHILENA}

\subsection{CONCEPTO Y NATURALEZA}

Junto a la anterior estructura institucional estatal, existen en el ordenamiento jurídico desde 1985 los Centros de Despacho Económico de Carga, más conocidos por su acrónimo CDEC. Estos son definidos en la legislación simplemente como "organismos encargados de determinar la operación del conjunto de instalaciones de un sistema eléctrico..." ${ }^{47}$. Es decir, corresponden a lo que en sistemas comparados se conoce como "operadores del mercado eléctrico", encargados de la elaboración de los programas de operación de las unidades generadoras en el corto y mediano plazo, así como de adoptar todas aquellas acciones tendientes a preservar la seguridad y la calidad del suministro de electricidad para los clientes finales.

Los CDEC son organismos que poseen, en principio, una naturaleza privada, lo que se deduce claramente de su integración y organización interna. Sin embargo, esta naturaleza no ha impedido al legislador atribuir a estos competencias muy relevantes en la coordinación del sistema ${ }^{48}$. Así, el legislador opta por un modelo privado de regulación, al menos parcial, de la operación del sistema, lo que se considera más eficiente para la gestión articulada de los agentes que intervienen en este mercado.

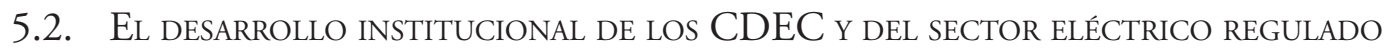

El CDEC-SIC fue el primero de los dos CDEC en ser creado en nuestro ordenamiento, y comenzó sus operaciones en 1985, bajo la regulación del Decreto Supremo No 6 , del Ministerio de Minería. Dado el carácter pionero de Chile en materia de privatización y

\footnotetext{
47 Artículo 225, letra "b", de la LGSE y al artículo $2^{\circ}$ del Reglamento que establece la estructura, funcionamiento y financiamiento de los CDEC (Decreto Supremo $N^{\circ}$ 291/2007). El mismo artículo indica que entre las instalaciones se incluyen "...las centrales eléctricas generadoras; líneas de transmisión a nivel troncal, subtransmisión y adicionales; subestaciones eléctricas, incluidas las subestaciones primarias de distribución y barras de consumo de usuarios no sometidos a regulación de precios abastecidos directamente desde instalaciones de un sistema de transmisión; interconectadas entre sí, que permite generar, transportar y distribuir energía eléctrica de un sistema eléctrico, de modo que el costo del abastecimiento eléctrico del sistema sea el mínimo posible, compatible con una confiabilidad prefijada".

${ }^{48}$ Esto ha generado algún debate doctrinario respecto de su naturaleza jurídica. La propia SEC lo ha calificado como "sui generis", carente de una naturaleza jurídica definida (véase, a modo ejemplar, Resolución Exenta $\mathrm{N}^{\circ}$ 1121 de 30 de junio de 2005, que aplicó sanciones a Empresa Eléctrica Guacolda, por transgresiones a la normativa vigente; disponible en <http://www.sec.cl/sitioweb/electricidad_sanciones/RE_1121.pdf>). De manera reciente, el informe del CADE recomendó "la creación de un CDEC independiente como Corporación de derecho privado, sin fines de lucro, que realiza una función de servicio público", señalando que entre sus características debía contar con patrimonio propio, estar regido por un consejo directivo conformado por expertos independientes y administrado por un Director Ejecutivo (CADE 2011) p. 85. Fuera de las imprecisiones jurídicas (por ejemplo, la relativa a la "función de servicio público"), nótese la similitud organizacional con la antigua CNE (supra sección 3.1). En un sentido similar, la llamada "Comisión Ciudadana Técnico-Parlamentaria" propuso "que los CDEC se constituyan en organismos independientes de las empresas generadoras, que su personal sea nombrado por el sistema de Alta Dirección Pública y financiado con fondos públicos" (CCTP 2011) p. 18. Como se observa, esta propuesta pretende "publificar" completamente los CDECs, rompiendo con el esquema actual de autorregulación. Por las razones que desarrollamos en el paper, no concordamos con esta radical postura.
} 
liberalización de este sector, no existían en ese entonces experiencias comparadas de las cuales fuera posible tomar ideas para su configuración institucional. En consecuencia, en línea con las bases de la regulación, el énfasis fue puesto en el carácter operativo de estos entes ${ }^{49}$.

En la práctica, el CDEC-SIC funcionaba como un verdadero "club" de generadores $^{50}$, conformado por solo tres empresas: Endesa, Chilgener y Colbún, esta última a esa fecha aún en manos estatales ${ }^{51}$. Se trataba de un organismo sin personal ni equipamiento propio, que fundamentalmente resolvía las tareas operativas a través del trabajo conjunto de las propias compañías. La Dirección de Operación (DO), el único órgano de funcionamiento interno contemplado en ese entonces, estaba formada por representantes de las propias compañías que conformaban el CDEC, y sus decisiones eran sometidas a revisión de un Directorio en el cual actuaban algunos de los mismos miembros de la DO u otros empleados de las firmas ${ }^{52}$. Esto permitió que, en términos generales, el proceso de toma de decisiones fuese en un comienzo fluido, centrado en aspectos técnicos, y carente de un mayor nivel de conflictividad ${ }^{53}$.

Sin embargo, como era esperable, la liberalización de algún modo "forzó" a una mayor apertura en la participación en el CDEC. La llegada de nuevos actores marcó, en los hechos, el fin de la colaboración y un aumento importante de la litigiosidad ${ }^{54}$. Los conflictos que en la práctica no lograban ser resueltos al interior del mismo Directorio del CDEC, denominados "divergencias", eran en ese entonces sometidos al pronunciamiento del Ministro de Economía, quien contaba con un plazo de 120 días para emitir su dictamen, previo informe de la $\mathrm{CNE}^{55}$. Con todo, dado el creciente aumento de las divergencias, dicho período fue cada vez más difícil de cumplir.

El Decreto Supremo No 327 de 1997, que reemplazó al DS 6/85, introdujo cambios en las tres áreas centrales a las que nos hemos referido. Primero, incorporó nuevos actores a los CDEC, algunos de ellos de manera obligatoria (transmisores) y otros de manera opcional (generadores de menor tamaño) ${ }^{56}$. Segundo, en materia de resolución de conflictos fue

\footnotetext{
49 De hecho, el artículo 2 del DS 6/85 indicaba que los propietarios de instalaciones sujetas a coordinación debían constituir "un Comité de Operación denominado Centro de Despacho Económico de Carga". A diferencia de este modelo netamente operacional, la mayor parte de los sistemas comparados privatizados que surgieron en las décadas posteriores enfatizaron la liberalización del mercado (esto es, la introducción de competencia a nivel de generación) y, por tanto, su principal preocupación radicó en mantener el acceso abierto a los sistemas de transmisión de manera no discriminatoria. Por esto, en la mayoría de ellos el operador del sistema es normalmente el mismo transmisor o una entidad vinculada a este.

50 Rudnick (2006) p. 7.

51 Podían participar en el CDEC todas las empresas generadoras con más de un $2 \%$ de la capacidad instalada total que tenía el sistema a la fecha de constitución del CDEC.

52 Artículos 7 y 10 del DS 6/85.

53 En los hechos, el funcionamiento no era muy distinto al que es posible encontrar en modelos no privatizados. Véase, por ejemplo, Cameron (2005: esp. cap. 7).

54 Pehuenche, filial de Endesa, en muchas ocasiones actuó con independencia en sus decisiones de esta.

55 Artículo 8, inciso $2^{\circ}$, del DS 6/85.

56 Se incorporaron obligatoriamente las compañías transmisoras que contaran con al menos un tramo de línea de longitud superior a $100 \mathrm{~km} \mathrm{y}$, de manera opcional, los generadores con potencia instalada superior a $9 \mathrm{MW}$. Con esto se pretendió reconocer, principalmente, la importancia que tiene la transmisión en la operación del sistema en Chile, cuya geografía exige redes extensas.
} 
creado un "Comité de Expertos" 57 que debía dar su opinión acerca de las divergencias de forma previa al pronunciamiento del Ministro, aunque sus recomendaciones no eran vinculantes ni para este ni para el Directorio del CDEC ${ }^{58}$.

Finalmente -en lo que constituiría el principal cambio del DS 327/97-, las tareas ejecutivas al interior de los CDEC fueron especializadas con la creación de la Dirección de Peajes (DP), a la cual, al igual que a la DO, le fueron asignadas funciones específicas establecidas por ley o por reglamento ${ }^{59}$. Ambas Direcciones fueron definidas como "entidades eminentemente técnicas y ejecutivas" y se les dotó de personal técnico propio ${ }^{60}$. Sin embargo, siguieron respondiendo de su desempeño ante el Directorio del CDEC respectivo ${ }^{61}$, el cual quedó a cargo del nombramiento de ambos Directores, así como de decidir acerca de su presupuesto, contratación de personal y evaluación de desempeño.

La alta litigiosidad que producía este esquema se reflejaría más tarde no solo en la constante presentación de divergencias ante el Ministro, quien, en la práctica, debía resolver acerca los procedimientos que eran de competencia de las direcciones técnicas y hacía las veces de operador "de hecho" del sistema en muchas materias; también se vería manifestada en una judicialización creciente de las decisiones ministeriales, solicitudes de incompetencia y demandas al Estado. Ello llevó a que en el año 2004, a través de la Ley $\mathrm{N}^{\circ}$ 19.940, se intentara subsanar estos problemas creando una nueva institucionalidad de solución de conflictos: el Panel de Expertos ${ }^{62}$. Este fue concebido como una instancia única y separada del Ministro, que debía pronunciarse en general sobre los conflictos del sector, incluyendo los surgidos al interior de un CDEC.

Por su parte, las deficiencias en los ámbitos de participación y administración del sector se intentaron comenzar a resolver un año más tarde, con la dictación de la Ley N² 20.018. En cuanto a la participación de los distintos actores que formaban parte del sector, fueron integradas al CDEC las compañías generadoras en general, las empresas de transmisión trocal y de subtransmisión y un representante de los clientes libres ${ }^{63}$. Asimismo, con la dictación del Decreto Supremo No 291, en el año 2007, las empresas dejan de formar parte directamente del Directorio y se crea la representación en base a segmentos o grupos de empresas representadas por dos o tres directores, según sea el caso, sobre un total de 10 directores, con sus respectivos suplentes. Como veremos, esta estructura se mantuvo por algo menos de una década, siendo modificada en el año 2012, con la dictación del Decreto Supremo N $115^{64}$.

\footnotetext{
57 El Comité estaba compuesto por un abogado y dos ingenieros de carácter independiente. Su nombramiento estaba originalmente a cargo del Directorio (artículo 176 letra "h" del DS 327/97).

${ }_{58}$ Esta característica, junto con la inidoneidad de algunos miembros, llevaron a que pocas veces sus recomendaciones fueran consideradas por el Ministro o por el propio CDEC.

59 El texto original del DS 327/97, en su artículo 173, establecía la posibilidad de que el Directorio encomendara "acciones de apoyo" o "tareas específicas" asociadas a las funciones del CDEC a un tercero.

${ }^{60}$ Artículo 180 del DS 327/97 original.

${ }^{61}$ Artículo 180 del DS 327/97 original.

62 El Panel está compuesto por siete profesionales, cinco de los cuales son ingenieros o licenciados en ciencias económicas y dos son abogados de amplia trayectoria profesional o académica y con dominio del sector. Su designación está a cargo del Tribunal de Defensa de la Libre Competencia.

${ }_{63}$ A raíz de este cambio, el Directorio del CDEC llegó a estar conformado por 16 representantes.

${ }^{64}$ Véase infra, sección 4.3.
} 
En materia de administración, en tanto, la independencia de las Direcciones de Operación y de Peajes fue reforzada, definiendo que la duración del cargo de director sería de cuatro años (con reelección por una sola $v^{2} z^{65}$ y estableciendo un presupuesto anual que debe ser informado favorablemente por la CNE en forma previa a su ejecución ${ }^{66}$.

\subsection{LOS CDEC EN LA ACTUALIDAD: MISIÓN, INTEGRACIÓN Y ESTRUCTURA INTERNA}

De acuerdo a lo señalado, la evolución de los CDEC ha estado marcado por los avances incrementales en tres aspectos: la participación de los agentes en dicho organismo, la forma de resolver los conflictos suscitados en su interior, y su estructura organizacional interna. En términos generales, en cada una de estas áreas, el foco de los avances ha estado puesto, respectivamente, en la apertura a nuevos actores, dotar de mayor eficacia y especialización a la resolución de los conflictos y procurar alcanzar una "profesionalización" e independencia de la administración de la organización.

Sin embargo, más allá de estos cambios, el objetivo principal ha permanecido invariable: mantener la operación del sistema de forma segura y económica, a lo que se sumó, posteriormente, el aseguramiento del acceso abierto a los sistemas de transmisión troncal y de subtransmisión ${ }^{67}$. Esto significa que cada CDEC define el funcionamiento del mercado en su respectivo sistema de manera privada, de forma independiente de las empresas que lo conforman, sujetos a criterios eminentemente técnicos. La lógica subyacente a esta opción regulatoria pareciera ser la confianza que tiene el legislador de que los privados tienen un mejor conocimiento de cómo alcanzar los objetivos establecidos para el sistema.

Como hemos visto, en un comienzo participación y administración del CDEC no eran más que las dos caras de una misma moneda. Actualmente, nuestro derecho ha optado porque cada CDEC esté conformado por empresas propietarias de instalaciones eléctricas del sistema, esto es, por las empresas generadoras, transmisoras troncales y de subtransmisión y los "clientes libres" no sometidos a regulación de precios del respectivo sistema que cuenten con instalaciones susceptibles de coordinación por parte del respectivo CDEC $^{68}$. Esta integración (que, como veremos, es la característica central que permite calificar al sistema como "corregulado" ${ }^{69}$ ) no responde a un diseño institucional predeterminado, sino

65 Para el nombramiento, reelección o remoción del DO o DP se exige el acuerdo de dos tercios del Directorio.

66 Este mismo año se dicta la Norma Técnica, cuya finalidad es orientar y acotar la actuación de los CDEC en la operación del sistema y aumentar la consistencia en los criterios de planificación y operación.

67 Artículos 137 y 138 de la LGSE. Respecto de los sistemas de transmisión, el artículo $77^{\circ}$ de la LGSE indica que: "Los propietarios de instalaciones de los sistemas de transmisión troncal y de los sistemas de subtransmisión no podrán negar el acceso al servicio de transporte o transmisión a ningún interesado por motivos de capacidad técnica, sin perjuicio de que, en virtud de las facultades que la ley o el reglamento le otorguen al centro de despacho económico de carga, en adelante CDEC, para la operación coordinada del sistema eléctrico, se limiten las inyecciones o retiros sin discriminar a los usuarios" (destacado agregado).

68 Artículo 225, letra "b", inciso tercero, de la LGSE, y artículo $4^{\circ}$ del Decreto Supremo No 291/2007. Nótese que la distribución nunca ha formado parte de los CDEC. El sistema fue diseñado originalmente para ser manejado exclusivamente por actores sujetos a obligaciones privadas. La distribución, en cambio, fue declarada servicio público y sometida a regulación directa (fundamentalmente de precios). El cambio en el carácter exclusivamente privado de las obligaciones de los integrantes del CDEC se produciría con la declaración de la transmisión como servicio público luego de la dictación de la Ley No 19.940 en el año 2004.

69 En el sentido expresado infra, en nota 92 y en el texto principal al que acompaña. 
a una necesidad coyuntural e histórica surgida con posterioridad a la privatización de las empresas, ante la ausencia de experiencia comparada sobre la materia, pero que se ha consolidado en la operación regular del sistema ${ }^{70}$.

En este modelo, todos los actores de un determinado sistema interconectado son coordinados por un CDEC, pero no todos son integrantes. Así, existen actores, propietarios de instalaciones eléctricas generalmente de menor tamaño relativo, que solo integran el CDEC de forma voluntaria, pues mantienen su opción de abstención. La diferencia entre ser o no integrante de un CDEC dice relación, principalmente, con la posibilidad de ejercer derechos de carácter político al interior de ese organismo ${ }^{71}$.

En cuanto a su estructura interna, a contar del año 2013, cada uno de los CDEC son supervisados por un Directorio de cinco miembros que representan a las empresas que integran el CDEC, pero que son independientes de estas ${ }^{72}$. Por su parte, su funcionamiento interno está encargado a cuatro "organismos eminentemente técnicos y ejecutivos" llamados "Direcciones Técnicas": la Dirección de Operaciones (DO), la Dirección de Peajes (DP), la Dirección de Planificación y Desarrollo (DPD) y la Dirección de Administración y Presupuesto $(\mathrm{DAP})^{73}$. Cada una de ellas es comandada por un director nombrado por el Directorio del CDEC respectivo, y tanto este como su personal deben ser idóneos e independientes para garantizar su "adecuado desempeño"74.

La evolución legal y reglamentaria de los CDEC hasta la actualidad es graficada en la siguiente tabla:

Tabla 1: Evolución legal y reglamentaria de los CDEC

\begin{tabular}{|c|c|c|c|c|}
\hline \multirow{2}{*}{$\begin{array}{c}\text { Instrumento } \\
\text { regulatorio }\end{array}$} & \multirow{2}{*}{ Participación } & \multicolumn{2}{|c|}{ Administración } & \multirow{2}{*}{$\begin{array}{c}\text { Resolución de } \\
\text { conflictos }\end{array}$} \\
\hline & & Directorio & Órganos internos & \\
\hline DS $6 / 1985$ & 3 generadoras & $\begin{array}{c}\text { Representantes de } \\
\text { empresas }\end{array}$ & $\begin{array}{c}\text { DO (a cargo de } \\
\text { representantes de } \\
\text { empresas) }\end{array}$ & $\begin{array}{l}\text { Ministro de } \\
\text { Economía }\end{array}$ \\
\hline DS 327/1997 & $\begin{array}{c}\text { Nuevos actores } \\
\text { (obligatorios y } \\
\text { opcionales) }\end{array}$ & $\begin{array}{c}\text { Representantes de } \\
\text { empresas }\end{array}$ & $\begin{array}{c}\text { Se crea DP } \\
\text { DO y DP a cargo de } \\
\text { directores dependientes } \\
\text { del Directorio }\end{array}$ & $\begin{array}{l}\text { Comité de } \\
\text { Expertos asesor } \\
\text { del Ministro }\end{array}$ \\
\hline Ley 19.940 & . & 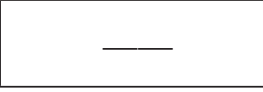 & $\begin{array}{c}\text { DO y DP asumen } \\
\text { rango legal }\end{array}$ & $\begin{array}{c}\text { Se crea el Panel de } \\
\text { Expertos }\end{array}$ \\
\hline
\end{tabular}

\footnotetext{
70 Supra, sección 4.2.

71 Además, los no integrantes no concurren al financiamiento del CDEC (artículo $7^{\circ}$ del DS 291/2007) ni tienen derecho a acceder o requerir cierto tipo de información que emana de las direcciones técnicas.

72 Artículos 22 y 23 del DS 291/2007, modificado por el DS 115/2012. Los directores duran tres años en sus cargos y pueden ser reelegidos hasta por dos períodos (Id., artículo 24).

73 Artículos 5 y 33 y ss. del DS 291/2007, modificado por el DS 115/2012. Como hemos indicado, el reglamento original (DS 6/85) solo contemplaba a la DO. La DP fue creada por el DS 327/97 (dotándosele, junto a la DO, de independencia); la DAP por el DS 291/07; y la DPD por el DS 115/2012.

74 Artículo 35 del DS 291/2007, modificado por el DS 115/2012.
} 


\begin{tabular}{|c|c|c|c|c|}
\hline $\begin{array}{l}\text { Ley } 20.018 \text { y } \\
\text { DS } 291 / 2007\end{array}$ & Mayor apertura & $\begin{array}{l}\text { Representación } \\
\text { por segmentos }\end{array}$ & $\begin{array}{c}\text { Independencia de DO } \\
\text { y DP } \\
\text { Se crea la DAP }\end{array}$ & - \\
\hline DS $115 / 2013^{*}$ & $\ldots$ & $\begin{array}{l}\text { Directorio con } \\
\text { integrantes } \\
\text { independientes } \\
\text { de las empresas } \\
\text { y reducción } \\
\text { del número de } \\
\text { directores }\end{array}$ & $\begin{array}{c}\text { Se crea DPD } \\
\text { Direcciones } \\
\text { dependientes del } \\
\text { Directorio (en cuanto } \\
\text { a nombramiento y } \\
\text { remoción) }\end{array}$ & \\
\hline
\end{tabular}

* El DS 115/2012 modifica el DS 291/2007.

Fuente: Elaboración propia.

Como se puede observar, los CDEC son órganos privados, integrados por las propias empresas del sector eléctrico y cuya finalidad es mantener la operación regular del sistema, operando como una instancia de autorregulación para hacer más eficiente la generación, transmisión y distribución del servicio. En el apartado siguiente analizamos cómo esta naturaleza y las facultades con que han sido dotados interactúan con aquellas establecidas para los organismos públicos sectoriales.

\section{LA ARTICULACIÓN PÚBLICA-PRIVADA DE LA INSTITUCIONALIDAD REGULATORIA ELÉCTRICA EN CHILE}

\subsection{La distribución de potestades en el modelo Regulatorio Vigente y su INTERPRETACIÓN ARMÓNICA \\ El complejo panorama institucional descrito en los dos acápites anteriores exige,} como es evidente, una articulación de las competencias de todos los órganos estatales y privados involucrados en la regulación y operación del sistema eléctrico en Chile. Ello exige una labor de interpretación de la normativa que distribuya correctamente las competencias asignadas a los distintos actores en juego. Para ello, la identificación precisa de los fines y objetivos atribuidos a cada organización y su relación con las potestades asignadas a cada uno de ellos constituye una operación fundamental para la comprensión y puesta en práctica del diseño institucional regulatorio.

Ahora bien, la distribución orgánica y competencial que supone la normativa sectorial no impide que se produzcan ciertos ámbitos convergentes, en los cuales será difícil determinar a priori la titularidad competencial en una materia determinada. Así, en el ámbito estrictamente normativo, por ejemplo, intervendrán de forma distinta el Ministerio de Energía, la CNE y la SEC; órganos administrativos que desplegarán (teóricamente) una actividad distinta, pero complementaria en el sector. Así, el Ministerio de Energía desarrolla la potestad normativa más relevante, ya que tiene asignada la atribución genérica sectorial para dictar las normas del sector ${ }^{75}$. Sin embargo, la CNE también tiene una participación parcial en la configuración normativa del ordenamiento sectorial, pero solo en la fijación

75 Artículo 4º letra "d", del DL N².224/78. 
de las normas técnicas y de calidad indispensables para el funcionamiento y la operación de las instalaciones energéticas ${ }^{76}$. A ello debe añadirse la potestad de la misma naturaleza que tiene la SEC en la generación de las normas técnicas que debe dictar para la aplicación de la $\mathrm{LGSE}^{77}$ y las potestades de autorregulación que se asignan a los CDEC para la fijación de sus procedimientos internos, la que es supervisada técnicamente por la CNE, como se analizará más adelante.

En este contexto, la compleja articulación de las potestades de cada uno de estos órganos exige, como ya se señaló, una interpretación sistemática y coherente de las distintas normas en juego, no pudiéndose interpretarse ninguna de ellas, en principio, como excluyentes de las otras, ya que ello negaría la existencia misma de la potestad y, por tanto, la validez de la norma excluida. De este modo, la habilitación normativa al Ministerio de Energía, por ejemplo, no puede suponer una atribución ilimitada de la regulación sectorial, sino que ella debe necesariamente mirarse como una prolongación formal de las atribuciones materiales asignadas a este órgano, con las restricciones que imponen las mismas normas jurídicas y los derechos establecidos en estas para las empresas que participan en el sector. Lo mismo ocurriría con la CNE, la que en el ejercicio de su potestad regulatoria técnica antes reseñada, no puede hacer inoperante la potestad normativa general del Ministerio de Energía, ni las potestades ordenadoras de la SEC o de los CDEC, ya que estas últimas se encuentran establecidas expresamente en el mismo ordenamiento jurídico.

Un criterio general que puede contribuir probablemente a esta interpretación armónica es, como ya se adelantó, atender al objetivo central que tiene asignado cada órgano en este sector material, lo que permite configurar cada atribución en relación a los bienes jurídicos o intereses públicos que el legislador ha puesto bajo su ámbito de acción. Así, en el caso del Ministerio de Energía, es evidente que el legislador lo ha configurado como un órgano de dirección política y administrativa, colaborando con el Presidente de la República en la definición de las políticas, planes, programas y normas del sector. A su vez la CNE está estructurada -como ya se señaló- como un organismo técnico, cuya misión principal es informar o elaborar documentos de estudio que permitan a la autoridad política o administrativa adoptar las decisiones regulatorias o de política pública del sector. Por su parte, la SEC tiene como objetivo la fiscalización y sanción de las empresas del sector, lo que implica el ejercicio más intenso de las potestades públicas de policía en este ámbito. En fin, los CDEC son órganos privados que deben ordenar los procedimientos de actuación de un grupo de operadores del sector, debiendo velar por el funcionamiento eficiente y seguro del mercado eléctrico.

Estos objetivos institucionales condicionan el ámbito de aplicación de sus potestades, debiendo realizarse una interpretación que permita el despliegue de cada una de estas para satisfacer los objetivos o intereses públicos puestos bajo su cargo.

\subsection{Las atribuciones de los CDEC y los órganos públicos Sectoriales}

Como hemos reiterado, los CDEC no fueron originalmente concebidos como organismos que respondan a un modelo regulatorio determinado, sino que surgieron

\footnotetext{
76 Artículo $7^{\circ}$, letra "b", del DL N².224/78.

77 Artículo 10 de la LGSE.
} 
consecuencialmente, como una necesidad de la operación, para cumplir fines específicos asociados a esta, particularmente la coordinación, no obstante su consolidación institucional posterior. Sin embargo, la legislación no señala los mecanismos específicos a través de los cuales se realiza esta, dejando entregados aquello a las normas emanadas de los propios $\mathrm{CDEC}^{78}$. Esto se concreta, en la práctica, en la habilitación específica a estos organismos, contenida en el DS 291/2007, para generar algunos instrumentos normativos apropiados, cuyo ámbito material está determinado por los objetivos de seguridad del sistema y garantía de la operación al mínimo costo que fija la ley.

Dentro de estos instrumentos, dos adquieren singular importancia. Primero, el reglamento interno, el cual, según señala el artículo 8, debe ser dictado por el Directorio para determinar el cumplimiento de las funciones del respectivo CDEC. Segundo, la generación de procedimientos técnicos, los que, según señala el artículo 10, deberán establecer las metodologías y los mecanismos de trabajo a través de los cuales se determinan los criterios, consideraciones y requerimientos de detalle que cada Dirección del CDEC necesita para el cumplimiento de las funciones y obligaciones que le son propias y determinar la regulación más eficiente de los distintos operadores que participan en el mercado eléctrico ${ }^{79}$.

Esta atribución de los CDEC supone una habilitación especial que hace el legislador a estas instancias privadas de coordinación de los operadores para disponer una autorregulación del sector, de manera que estos deban operar coordinadamente en la generación, transmisión y distribución de la energía eléctrica ${ }^{80}$. Esta habilitación normativa a un órgano privado se conecta con lo que la doctrina administrativa denomina "autorregulación técnica”, y que implica generar una forma novedosa del Estado de realizar su actividad de ordenación -en el ámbito de la actividad policía-, incorporando a los privados en la generación de su propio marco regulatorio, sin perjuicio de la intervención posterior de la autoridad pública competente ${ }^{81}$.

En este contexto, en el caso que nos ocupa, el reglamento correspondiente consagra una atribución general a los CDEC para disponer instrucciones, procedimientos y mecanismos para la coordinación general del sistema ${ }^{82}$, atribución que es el resultado de sucesivas modificaciones reglamentarias que la han ido configurando de manera cada vez más clara y precisa ${ }^{83}$. Así, el diseño legislativo optó por atribuir a los propios operadores del sistema eléctrico la regulación de su actividad, permitiendo la coordinación privada de estos, en el marco de las disposiciones generales establecidas en el ordenamiento jurídico.

\footnotetext{
78 LGSE, artículo 225, letra "b”. El mismo artículo solo establece la obligatoriedad de que "el costo del abastecimiento eléctrico del sistema sea el mínimo posible, compatible con una confiabilidad prefijada”.

79 El antecedente de estos "procedimientos" (DO/DP/DAP/DPD, según sea el caso) se encuentra en los llamados "Manuales de Procedimiento", incorporados en el DS 327/97.

80 Artículos 127, 138, 150 y 225, letra "b”, de la LGSE.

81 SÁnchez Morón (2007) pp. 629-31.

82 Artículo $3^{\circ}$ del DS 291/2007.

83 Bajo el esquema del DS 6/85, los procedimientos formaban parte de los propios Reglamentos Internos. Luego, bajo la vigencia del DS 327/97, los Manuales de Procedimiento consagraron la autorregulación, los cuales pasaron a ser los "procedimientos" actuales bajo el DS 297/07.
} 
Por esta misma razón, se les reconoce a los operadores de ese mercado y miembros del CDEC un derecho de participación en la generación de las propias normas y procedimientos internos del órgano regulador, pudiendo manifestar incluso sus observaciones técnicas o de legalidad del procedimiento propuesto, e incluso impugnarlo ante el Panel de Expertos, de acuerdo al procedimiento de resolución de controversias establecido en los artículos 208 y ss. de la LGSE. Esta especial consideración que hace el reglamento por los propios operadores del sistema, permitiendo su conocimiento e impugnación antes de su formalización, constituye una técnica regulatoria que busca evidentemente una mayor cercanía, compromiso y efectividad de la norma dictada, superando así a la técnica de la mera participación privada en la generación de la norma pública ${ }^{84}$. Así, son los actores del mercado, agrupados en un CDEC, los que generan inicialmente las normas y procedimientos técnicos de operación, y no la autoridad pública, como es lo habitual en la regulación de la actividad privada de interés público.

Por otra parte, la normativa emanada de los CDEC se debe sujetar, en términos generales, a las normas y reglamentos que proponga la CNE, y que dicte el Presidente el República, a través del Ministerio de Energía. Asimismo, de manera específica, la ley y el reglamento han dispuesto una potestad de supervisión de la CNE de las actuaciones de los CDEC. Esto supone la exigencia de una aprobación formal de los procedimientos y normas propuestas por el órgano privado por parte de la instancia técnica de la Administración del Estado, configurándose actualmente como un verdadero "poder de veto" sobre esta regulación sectorial, cautelando de esta manera rigurosamente los intereses generales envueltos en esta materia.

Así el "informe favorable" de la autoridad exigido en este caso se construye como un "informe vinculante" para los CDEC, similar a los establecidos en los procedimientos administrativos ordinarios, cuya sujeción es obligatoria o preceptiva para el ente privado, no pudiendo omitir su cumplimiento ${ }^{85}$. En este sentido este trámite opera como una verdadera autorización administrativa, operando así la Administración a través de una clásica técnica de control preventivo para resguardar el cumplimiento y la tutela del ordenamiento jurídico y la satisfacción de los fines que este establece en esta materia ${ }^{86}$.

Nótese que el ámbito de esta potestad administrativa ha ido variando en el tiempo en esta materia. Bajo la vigencia del DS 6/1985, los CDEC solo debían enviar informes periódicos a la CNE acerca de su actuar ${ }^{87}$; facultad que ha pasado a la actual normativa bajo la forma de un requerimiento general de información ${ }^{88}$. Esta supervisión "liviana" (de light

\footnotetext{
84 Sobre la participación como técnica de intervención de los privados en la generación de la regulación estatal, y su importancia en el Derecho Administrativo actual, puede verse SCHMidT-Assmann (2003: 118-122).

85 Santamaría Pastor (2005) pp. 64-5.

86 Parada (1998) pp. 446-47.

87 Artículo 38 del DS 6/85 (informes mensuales y anules). El artículo $8 \mathrm{~N}^{\circ} 2$ del mismo cuerpo legal establecía que los informes debían ser aprobados por el Directorio.

${ }_{88}$ El artículo 31 del DS 291/07 (modificado por el DS 115/12) dispone que el Directorio debe hacer entrega de un "informe resumido" dentro de los 10 primeros días de cada mes, conteniendo la información que allí se indica. El antiguo artículo 40 del DS 6/85, antecesor de esta disposición, disponía él mismo que la falta de envío del informe en tiempo y forma era sancionable por la autoridad.
} 
touch, en términos anglosajones) se mantendría hasta la dictación del DS 291/07, cuando la potestad supervisora fue profundizada por el legislador, confiriéndosele a la CNE una tutela normativa específica sobre el reglamento interno y los "procedimientos" emanados de cada una de las direcciones. Desde entonces, la potestad de supervisión se expresa concretamente en un "informe favorable" del reglamento interno y de los procedimientos técnicos dispuestos por el CDEC.

Este informe favorable, atendido el objetivo principal que el legislador ha atribuido a la CNE en el sector -según hemos visto, un órgano establecido como esencialmente "técnico"-, debiera circunscribirse lógicamente a la evaluación técnica del procedimiento o norma propuesta por el CDEC, en el marco de los objetivos generales de seguridad y confianza establecidos para el sistema eléctrico. Así, la CNE no podría extender su informe, en principio, a aspectos relacionados con la conveniencia de la política pública u opción procedimental adoptada por el CDEC, ya que ello excede el marco de competencias que le ha sido asignado en esta materia a la Comisión.

En este sentido, el "informe favorable" que debe emitir la CNE se encuentra acotada a la función general atribuida a este órgano por el ordenamiento jurídico ${ }^{89}$, que lo configura como un órgano estrictamente técnico, con atribuciones consultivas y asesoras en el sector, fuera del ámbito de la decisión de la política pública, la fiscalización y la represión, campos que han sido asignados a otros órganos estatales.

Por otro lado, la CNE tampoco podría, al momento de conocer el procedimiento técnico enviado por el CDEC, introducir modificaciones, ni reemplazar la propuesta enviada por este, ya que la ley le asigna estrictamente una facultad de "informar favorablemente" aquel o no hacerlo, en caso de que discrepe técnicamente de la medida propuesta por el CDEC, pero no asumir roles de coautor de la normativa o procedimiento propuesto. De acuerdo a esto, si bien es cierto que el informe de la CNE tiene un carácter preceptivo para la entrada en vigencia de la norma o procedimiento, ello no implica que dicha autoridad pueda atribuirse facultades normativas directas en esta materia, ya que estaría suplantando al órgano de autorregulación dispuesto por la ley, dando lugar a otra técnica de participación del sector privado en la regulación sectorial.

En este contexto, parece no haber dudas de que la CNE carece de potestades regulatorias directas para disponer los procedimientos de operación de los CDEC, ya que son estos últimos los titulares de la atribución y no aquella. Cierto es que la ley le otorga a la CNE una potestad regulatoria técnica y de calidad en su ley orgánica ${ }^{90}$, pero ella solo opera en los casos que señala la ley -como lo indica el propio precepto citado-, y no como una habilitación general para desplegar una potestad normativa general. Así, en el caso del artículo 137 de la LGSE, la habilitación normativa está dispuesta solo para establecer las formas de coordinación que deberán disponer los CDEC, pero no como una potestad regulatoria general directa sobre la actividad de estos ${ }^{91}$.

89 Artículo $6^{\circ}$ inciso $2^{\circ}$ del $\mathrm{DL} \mathrm{N}^{\circ} 2.224 / 78$.

90 Artículo $7^{\circ}$, letra “b”, del DL N².224/78.

91 Confirma esta conclusión el tenor de lo dispuesto en la letra “a” del artículo $7^{\circ}$ del Decreto Ley $\mathrm{N}^{\circ} 2.224$, que al referirse a la estructura del nivel de precios y tarifas, aspecto relevante de la operación de las empresas generadoras y distribuidoras, esta atribución a la Comisión se circunscribe al "análisis técnico" de las medidas, 
Por último, si la CNE rechazare el procedimiento propuesto, enunciando los motivos o fundamentos para ello, el CDEC evidentemente podría modificar la propuesta envia$\mathrm{da}$, introduciendo los cambios que estime necesarios para superar las objeciones planteadas por aquella, pero sin que sea admisible que la CNE determine el contenido de esa nueva propuesta, más allá de los condicionamientos técnicos que imponga su informe desfavorable a la propuesta procedimental enviada.

En el mismo sentido ante apuntado se ha pronunciado recientemente la Contraloría General de la República, mediante Dictamen N 70.637, de 30 de octubre de 2013, a propósito de una intervención de la CNE regulando directamente un procedimiento que corresponde diseñar a una dirección de un CDEC. En efecto, el órgano contralor señaló que “...la Comisión (CNE), en el marco de la elaboración del Procedimiento respectivo, ha de limitarse, únicamente, mediante acto administrativo pertinente, a evacuar su informe favorable, o bien, en el evento de que dicho servicio estime que no se dan las condiciones para ello, a expresar las razones que le impiden hacerlo -en la medida, naturalmente, que no se trate de aspectos resueltos por el Panel de Expertos en el ámbito de sus atribuciones, cuando haya tenido lugar esa instancia-, sin que la autoridad esté facultada para intervenir su texto de manera directa, siendo dable agregar que, en todo caso, el acto administrativo que emita al efecto dicho organismo estatal está sujeto a las reglas generales en materia de impugnación".

\subsection{El MODELO DE “CORREGULACIÓN” PÚBLICO-PRIVADO RESUlTANTE}

De todo lo antes expuesto queda en evidencia que la forma actual de organizar la coordinación de la operación de las instalaciones eléctricas interconectadas, con un rol tan relevante de entidades privadas asociativas, responde a una estructura autorregulatoria que la literatura denomina específicamente "corregulación"; esto es, un mecanismo de regulación privado integrado institucionalmente en un marco de control estatal, expresado específicamente en la ratificación de la normativa privada por el órgano público ${ }^{92}$.

Este modelo, desde luego, puede ser objeto de críticas. En nuestro derecho, destacan al menos dos fundamentales: por un lado supone, en principio, una atribución de competencias regulatorias a un ente privado, ajeno a la Administración del Estado; por otro, deriva a un reglamento la definición de las competencias y mecanismos específicos en esta materia, alterando, aparentemente, la regla de reserva legal establecida en el artículo 65, inciso $4^{\circ}$, del numeral 2 de la Constitución Política de la República.

Respecto de lo primero, la cuestión es compleja, ya que el artículo $6^{\circ}$ de la LOCBGAE señala claramente que las entidades que no formen parte de la Administración "no podrán, en caso alguno, ejercer potestades públicas", es decir, prerrogativas o atribuciones que supongan ejercicio de potestad mando respecto de las demás personas. Dentro de estas

siendo concordante con la función genérica de asesoría asignada a la CNE en el artículo $6^{\circ}$ de la misma ley. Aún más, toda la función general asignada a la $\mathrm{CNE}$ en esta materia, en el mismo artículo $6^{\circ}$, como órgano técnico del sector, está precedida del verbo "analizar", referido esta a los "precios, tarifas y normas técnicas".

92 Véase supra, sección I. Debemos insistir en que a pesar de su denominación, la corregulación es una forma de autorregulación que no implica regulación "conjunta" entre el ente público y el privado, sino solo un poder de ratificación entregado a la administración. 
claramente está la potestad normativa o regulatoria, ya que la posibilidad de dictar normas que se impongan a terceros constituye una típica expresión de poder público en el ordenamiento jurídico chileno ${ }^{93}$. No obstante, esta regla legal no impide que los sujetos privados puedan adoptar normas obligatorias para ellos mismos, ejerciendo así una potestad autorregulatoria derivada de su propia autonomía y libertad para el desarrollo de actividades económicas. Así, la potestad normativa de los CDEC aparece como perfectamente compatible con el ordenamiento jurídico, en la medida que no se configura como una potestad normativa derivada ni delegada de la Administración del Estado, sino ejercicio de su propia libertad organizativa.

Esta misma explicación permite salvar la segunda objeción planteada: la regulación reglamentaria de sus competencias. Al configurarse los CDEC como entes privados, sus funciones y atribuciones pueden estar establecidas en una norma reglamentaria, ya que la reserva legal establecida en el artículo $65 \mathrm{~N}^{\circ} 2$ de la Constitución está referida a los servicios públicos, denominación que solo alcanza a los entes que integran orgánicamente la Administración del Estado. Así, la atribución de facultades de coordinación a un ente privado como los CDEC no afecta de forma alguna el ordenamiento constitucional, el que -reiteramos- solo está referido a los órganos públicos.

Estas dos afirmaciones generan al menos dos conclusiones relevantes para el sector eléctrico. La primera de ellas, y más evidente, es que las facultades de los CDEC para coordinar a las empresas eléctricas que se encuentran interconectadas constituye una expresión de autorregulación reconocida por el legislador, pero que no tiene la entidad, ni la naturaleza de una regulación dispuesta en el ejercicio de una potestad pública. Esto lleva a que los procedimientos dispuestos por cada una de las Direcciones de los $\mathrm{CDEC}^{94}$ sean mecanismos de coordinación interna de los asociados, que permiten el funcionamiento ordenado del sistema eléctrico, pero que no pueden imponer obligaciones jurídicas adicionales a los operadores del sector, salvo aquellas que se deriven de la propia ley o de los reglamentos establecidos en conformidad a esta.

La segunda conclusión, complementaria de la anterior, es que los CDEC se encuentran limitados en su campo de acción a las metodologías y mecanismos técnicos de operación de las empresas, de acuerdo a las disposiciones legales y reglamentarias que regulan el sector, como lo señala el artículo 10 del DS 291/2007. Así, el ordenamiento jurídico establece un ámbito material de la regulación dispuesta a través de este mecanismo, no pudiendo extenderse a otros campos o áreas no establecidas en el reglamento.

En suma, la habilitación que hace la LGSE y el reglamento a los CDEC para la regulación sectorial tiene la característica de habilitar un mecanismo de corregulación de los operadores, opción que puede parecer apropiada, atendida la naturaleza de la actividad regulada. Así, la CNE asume una labor esencialmente supervisora de la regularidad procedimental, cautelando el cumplimiento por parte del CDEC de los objetivos y finalidades dispuestas en la ley y resguardando el interés público comprometido.

93 Ver, en este sentido, Ferrada (2007) pp. 78-79.

${ }^{4}$ En virtud de las habilitaciones establecidas en los artículos 10, 36 letra "k" y 37 letras "a" y "d" del DS $291 / 2007$. 


\subsection{El ForTALECIMiento DEL MODElo CORREGULATORIO O AUTORREGULATORIO Y LAS}

\section{MEDIDAS CONTRADICTORIAS DE LA AUTORIDAD}

Este modelo corregulatorio antes descrito diseño por el legislador, sin embargo, ha sufrido algunos embates por la propia autoridad administrativa, adoptando medidas que van en el sentido contrario al diseño institucional planteado. En este sentido, el año 2012 la autoridad administrativa publicó el "Reglamento de Servicios Complementarios" en el que confirió a los CDEC explícitas facultades de planificación de las inversiones que deben realizar los agentes privados en esta materia, excediendo el marco de mera coordinación técnica establecido para aquellos. Así se establece en el inciso segundo del artículo $5^{\circ}$ de dicho Reglamento, que los respectivos CDEC, a través de su DO, deberán "identificar los recursos existentes y disponibles en el sistema”, pudiendo, a partir de lo anterior "instruir... la instalación y/o habilitación obligatoria de los equipos" necesarios para efectuar la coordinación del sistema eléctrico ${ }^{96}$.

La primera de estas facultades -la identificación- parece compatible con lo dispuesto en el artículo $150^{\circ}$ inciso $1^{\circ}$ de la LGSE, que establece que son las empresas las que "disponen" de servicios complementarios y que al respectivo CDEC, dentro de ese universo, le corresponde definir lo que estime necesarios para la coordinación, administración y operación ${ }^{97}$. Sin embargo, la segunda facultad referida parece ir más allá del marco establecido por el legislador, desde que autoriza a los CDEC a (i) exigir a los agentes privados a "instalar" equipos, cuando estos no existen en el sistema; y (ii) forzarlos a interconectar sus equipos preexistentes (esto es, "habilitarlos"), cuando estos están desvinculados del sistema.

En la práctica, con el otorgamiento de esta facultad por la autoridad administrativa, a través del Reglamento de Servicios Complementarios, se transforma a los CDEC en una especie de entes planificadores centralizados de las inversiones, desnaturalizando su función

\footnotetext{
95 Decreto 130 de 2011, del Ministerio de Energía, publicado en el D.O. con fecha 31 de diciembre de 2012, que aprueba reglamento que establece las disposiciones aplicables a los servicios complementarios con que deberá contar cada sistema eléctrico para la coordinación de la operación del sistema en los términos a que se refiere el artículo $137^{\circ}$ de la Ley General de Servicios Eléctricos.

96 El artículo $5^{\circ}$ del Reglamento de Servicios Complementarios indica que "Corresponderá a cada Dirección de Operación, en adelante e indistintamente la o las DO, de cada [CDEC], la definición, administración y operación de los servicios complementarios necesarios para garantizar que la operación del sistema respectivo cumpla con las exigencias y sus condiciones de aplicación definidas en la NTSyCS a que se refiere el artículo anterior, minimizando el costo de operación del respectivo sistema eléctrico. // Para tales efectos, corresponderá a la DO identificar los recursos existentes y disponibles en el sistema, a partir de lo cual deberá instruir, a quien determine, la instalación y/o habilitación obligatoria de los equipos con los que deberá contar el sistema eléctrico respectivo para la coordinación de la operación a que se refiere el artículo $137^{\circ}$ de la Ley, a fin de establecer y preservar la seguridad y calidad de servicio definidos en la NTSyCS, en los casos que establezca el presente reglamento" (énfasis agregado).

${ }^{7}$ En el proyecto de ley que introdujo el artículo $150^{\circ}$ de la LGSE indicó que "por tratarse de un mercado de alta especificidad técnica y económica, [se propone] que la identificación y definición de los servicios complementarios se realice a través del reglamento, definiéndose estos conforme a las condiciones y características especiales de cada sistema eléctrico". En el párrafo inmediatamente siguiente se señala que "La administración y operación de estos servicios complementarios será realizara por el organismos [sic] coordinador de la operación en cada sistema (el CDEC respectivo), en base a garantizar la operación más económica para el sistema eléctrico" (Id., p. 21, énfasis agregados).
} 
eminentemente técnica de coordinación y operación del sistema ${ }^{98}$. Con esto, el aludido Reglamento fortalece el carácter autorregulatorio del modelo eléctrico chileno, pero incrementa indebidamente el campo de acción de los CDEC, convirtiéndolos en entidades privadas con verdaderas potestades públicas.

Esta ampliación notable de las atribuciones de los CDEC no solo los desnaturalizan, sino que incluso les confiere una prerrogativa superior a aquellas de naturaleza similar que la propia normativa sectorial ha otorgado a los reguladores. Por ejemplo, la CNE está facultada para "determinar" un programa de obras de generación y transmisión (conocido como "Programa de Obras") para efectos de la fijación semestral del precio de nudo (uno de los precios de la electricidad) que realiza dicho organismo ${ }^{99}$. No obstante, esta determinación es meramente indicativa de las obras que deben realizarse y tiene una naturaleza funcional a la fijación tarifaria ${ }^{100}$.

Por otra parte, la facultad reconocida a los CDEC de exigir "habilitar" equipos que permanecen desconectados del sistema implica el establecimiento de una verdadera obligación de interconexión impuesta sobre los propietarios de las instalaciones, pero sin que concurra ninguno de los presupuestos legales para ello. En efecto, la LGSE subordina esta obligación al cumplimiento de dos requisitos: (i) que sea determinada por el Ministerio de Energía mediante decreto supremo, previo informe de la CNE; y (ii) que solo recaiga sobre concesionarios (que no son todos los actores de la industria eléctrica ni todos los generadores ${ }^{101}$. El hecho que la interconexión requiera de este estatuto especial en nuestro derecho, es consistente con el marco eminentemente privado en que se desarrolla la generación eléctrica en Chile. Si la prestación de los servicios principales (esto es, energía y potencia) no está determinada por un ente planificador, sino por el libre juego de la oferta y la

98 Esto contraviene la naturaleza jurídica eminentemente técnica de los CDEC y sus direcciones internas. En efecto, el reglamento entrega la facultad a la DO del respectivo CDEC, la cual es referida en la LGSE como un organismo "técnico necesario para el cumplimiento de su operación” (LGSE, artículo 225, letra "b", inciso $2^{\circ}$ ). Allí mismo se reitera que se trata de organismos "eminentemente técnicos y ejecutivos". Asimismo, la normativa eléctrica es clara en establecer que la función de los CDEC se circunscribe al ámbito de la coordinación. La propia definición legal del artículo 225 letra b) de la LGSE, indica que se trata de organismos encargados de "determinar la operación del conjunto de instalaciones de un sistema eléctrico [...]" (énfasis agregado). Así también lo ha reconocido la doctrina. Por ejemplo, Sepúlveda (2010: 68) indica que "En el caso chileno, ambas coordinaciones [física y de intercambio de productos y servicios] se han concentrado en una misma entidad, el Centro de Despacho Económico de Carga para los sistemas interconectados del centro y norte grande del país (SIC y SING)" (énfasis agregado). La sección bajo la cual aparece esta cita se denomina precisamente "El organismo coordinador: Centro de Despacho Económico de Carga” (Id.: 67).

99 Artículo 162 de la LGSE.

100 Así lo confirma la propia CNE en su sitio web, donde se define al Plan de Obras de la siguiente forma: "Corresponde al programa que determina semestralmente la CNE en la fijación de precio de nudo. Su aplicación es solo para los efectos tarifarios establecidos en la normativa y no es vinculante para construcción de cobras, es decir tiene carácter indicativo. [...]" (énfasis agregado). Véase www.cne.cl/glosario (última visita: 23.09.2013).

101 El artículo $137^{\circ}$ inciso $1^{\circ}$ de la LGSE indica: "Los concesionarios de cualquier naturaleza están obligados a llevar a cabo la interconexión de sus instalaciones cuando con informe de la Comisión se determine mediante decreto supremo del Ministerio de Energía”. Nótese que solo una vez establecida la interconexión nace la obligación de coordinación (artículos $137^{\circ}$ inciso $2^{\circ}$ y $138^{\circ}$ de la LGSE), por la cual velan los CDEC, y la obligación de información que facilita la anterior (artículo $138^{\circ}$ de la LGSE). 
demanda, de acuerdo al modelo institucional chileno, la prestación de servicios adicionales o complementarios debe seguir también esa misma lógica.

La competencia y libre iniciativa privada que inspiran el modelo chileno implican que la prestación de servicios complementarios debiera interpretarse en un contexto de mercado $^{102}$. Esto quiere decir que son los CDEC los que, en la operación del mercado, deben entregar las señales de precio adecuadas para que sean las firmas quienes realicen las inversiones en los servicios complementarios que se definan como necesarios ${ }^{103}$. Por el contrario, la regulación de carácter más mandatorio consagrada en el Reglamento de Servicios Complementarios contraviene el adecuado balance entre potestades públicas y ámbito privado de regulación que existe, y debe existir, en el sistema eléctrico actual.

\section{CONCLUSIONES}

De lo expuesto, es posible formular las siguientes conclusiones centrales:

1. El sistema eléctrico chileno descansa en un complejo modelo que articula entidades públicas y privadas, distribuyendo las tareas entre estas de acuerdo a los objetivos establecidos por el ordenamiento en cada caso. Este modelo no fue explícitamente "diseñado", sino que constituye un mero reflejo legal de la evolución histórica del sector.

2. En este modelo, los órganos públicos sectoriales comparten el rol regulatorio del sector con los CDEC, generando un modelo de autorregulación conocido como "corregulatorio", con competencias diferenciadas y articuladas por el propio ordenamiento. Así, los CDEC se articulan como órganos autorreguladores privados del sector, sujetos a la supervisión y, en determinados casos específicos, ratificación de su actuación por parte de la autoridad.

3. La autoridad estatal, por la vía reglamentaria, ha tratado de desnaturalizar este modelo, ampliando o reduciendo las atribuciones de los CDEC en ciertos ámbitos, generando soluciones confusas para el funcionamiento eficiente del sistema y, en ocasiones, abiertamente contradictorias con la adecuada distribución competencial establecida en este último.

4. A estas alturas, parece indispensable reflexionar sobre el modelo regulatorio chileno, diseñando con mayor precisión su estructura orgánica y sus instrumentos y

\footnotetext{
102 Así queda claro en la historia de la ley que introdujo el actual artículo $150^{\circ}$ de la LGSE. A lo largo de la discusión parlamentaria se dejó en claro que el objetivo era tender a la "[f]ormalización de un mercado de servicios complementarios destinados a conferir mayor confiabilidad a los sistemas eléctricos" y que lo que el Ejecutivo pretendió fue "[i]ntroducir un sistema de remuneración de servicios complementarios en la operación de los sistemas, que incentive inversiones y modos de operación que favorezcan la confiabilidad y calidad, y reduzcan los costos de operación" ("Historia de la Ley N 19.940, que Regula Sistemas de Transporte de Energía Eléctrica, establece un Nuevo Régimen de Tarifas para Sistemas Eléctricos Medianos e Introduce las Adecuaciones que indica a la Ley General de Servicios Eléctricos”, Biblioteca del Congreso Nacional, 13 de marzo de 2004, p. 9, énfasis agregados). La "formalización del mercado" a que se hace referencia pretende destacar el hecho que se trataba de servicios que existían, pero no se valorizaban.

103 Esta señal, en la mayoría de los casos, va asociada a la señal de precio necesaria para la entrega del producto principal, pues los mismos equipos sirven para proveer servicios complementarios
} 
mecanismos de regulación, en base a los principios que lo fundan y articulan. Esto permitirá un desarrollo más coherente, eficiente y eficaz del sistema, para beneficio de los consumidores.

\section{BIBLIOGRAFÍA CITADA}

Alé, Jorge (1990): “Un nuevo esquema de regulación de monopolios naturales”, en Estudios Públicos, vol. 37: pp. 165-226.

Ayres, Ian y John Braithwaite (1992): Responsive Regulation: Transcending the Deregulation Debate (Oxford University Press).

Baldwin, Robert, Martin Cave y Martin Lodge (2012): Understanding Regulation: Theory, Strategy and Practice (Oxford University Press, segunda edición).

Balleisen, Edward J. (2010): “The Prospects for Effective Coregulation in the United States: A Historian's View from the Early Twenty-First Century" (E. Balleisen \& E. Moss, eds.) en: Government and Markets: Towards a New Theory of Regulation (Cambridge University Press) pp. 443-481.

Balleisen, Edward J. y Marc A. Eisner (2009): "The Promise and Pitfall of Co-Regulation: How Governments can Draw on Private Governance for Public Purpose" (Moss \& Cisternino, eds.) en: New Perspectives on Regulation (The Tobin Project) pp. 127-149.

BLACK, Julia (2001): "Decentring Regulation: The Role of Regulation and Self-Regulation in a 'Post-Regulatory World'”, Current Legal Problems: pp. 103-46.

Black, Julia (1997): "An Economic Analysis of Regulation: One View of the Cathedral”, Oxford Journal of Legal Studies, vol. 16: pp. 699 y ss.

BRAITHWAITE, John (2008): Regulatory Capitalism: How it works, ideas for making it work better (Edward Elgar).

Cameron, Peter D. (ed.) (2005): Legal Aspects of EU Energy Regulation - Implementing the New Directives on Electricity and Gas across Europe (Oxford University Press).

Coglianese, Cary y Evan Mendelson (2010): "Meta-Regulation and Self-Regulation" (R. Baldwin, M. Cave \& M. Lodge, eds.) en: The Oxford Handbook of Regulation (Oxford University Press) pp. 146-168.

Comisión Asesora para el Desarrollo Eléctrico (CADE) (2011): “informe”, noviembre 2011.

Comisión Ciudadana Técnico-Parlamentaria (CCTP) (2011): "Chile Necesita una Gran Reforma Energética: Propuestas de la Comisión Ciudadana Técnico-Parlamentaria para la Transición hacia un Desarrollo Eléctrico Limpio, Seguro, Sustentable y Justo”. Informe, octubre 2011.

Estache, Antonio y Martín Rodríguez-Pardina (2000): "Reforming the electricity sectors in the Southern Cone: the Chilean and Argentine experiments" (L. Manzzeti, ed.) en: Regulatory Policy in Latin America: Post-Privatization Realities (North South Center Press, University of Miami).

Ferrada, Juan Carlos (2007): "Potestades y privilegios de la Administración Pública en el régimen administrativo chileno", Revista de Derecho, Universidad Austral de Chile, vol. XX, No 2: pp. 69-94. 
Fisher, Ronald y Pablo Serra (2007): "Efectos de la Privatización de Servicios Públicos en Chile”. Banco Interamericano de Desarrollo, ConoSur: Serie de estudios económicos y sociales, documento CSC 07-009 (agosto).

Grabosky, Peter y John Braithwaite (1986): Of Manners Gentle: Enforcement Strategies of Australian Business Regulatory Agencies (Oxford University Press).

NúN̄EZ, Javier (2002): “¿Puede la autorregulación proteger contra el fraude y la negligencia?”, en Revista Perspectivas (Departamento de Ingeniería Industrial, Universidad de Chile), vol. 6(1): pp. 111-128.

Ogus, Anthony (1995): "Rethinking Self-Regulation", Oxford Journal of Legal Studies, vol. 15: pp. 97 y ss.

Parada, Ramón (1998): Derecho Administrativo, Parte General I (Marcial Pons).

Paredes, Ricardo y SAPag, José Manuel (2001): Fortalezas y Debilidades del Marco Regulatorio Eléctrico Chileno: Propuestas para un Cambio (Ciade, Universidad de Chile).

Parker, Christine (2002): The Open Corporation: Effective Self-Regulation and Democracy. (Cambridge University Press).

Pollitt, Michael (2004): "Electricity Reform in Chile: Lessons from Developing Countries", Journal of Network Industries, vol. 5(3): pp. 221-62.

RUDNICK, Hugh (2006): "Un nuevo operador independiente de los mercados eléctricos chilenos”, Estudios Públicos, vol. 101 (verano): pp. 1-26.

Rudnick, Hugh y Cristian Álvarez (2001): "Análisis comparativo de la gobernabilidad de mercados de generación eléctrica", ICSECIT 2001, International Conference on System Engineering, Communications and Information Technologies (17-19 de abril de 2001), Universidad de Magallanes, Punta Arenas, Chile, disponible en <http://web.ing.puc. $\mathrm{cl} / \sim$ power/paperspdf/alvarezicsecit.pdf $>$ (última visita: 19.11.2013).

Sánchez Morón, Miguel (2007): Derecho Administrativo (Tecnos).

Santamaría Pastor, Juan Alfonso (2005): Principios de Derecho Administrativo General, tomo II (Iustel).

Schmidt-Assmann, Eberhard (2003): La teoría general del Derecho Administrativo como sistema (Marcial Pons).

Sepúlveda, Enrique (2010): Sistema y Mercado Eléctricos (Legal Publishing).

Serra, Pablo (2002): "Regulación del Sector Eléctrico Chileno", Perspectivas, vol. 6(1): pp. $11-44$.

SinClair, Darren (1997): "Self-Regulation versus Command and Control? Beyond False Dichotomies”, Law \& Policy, vol. 19: pp. 529-59.

Soto, Raimundo, Felipe Morandé, Rafael Charún y Ricardo Raineri (eds.): La Industria Eléctrica en Chile: Aspectos Económicos (Ilades).

Spulber, Daniel F. (1989): Regulation and Markets (The MIT Press).

Vergara, Alejandro (2011): Código de Energía - Sistematización de leyes anotadas y actualizadas (Abeledo Perrot, Legal Publishing Chile).

Vogel, Steve K. (1996): Freer Markets, More Rules: Regulatory Reform in Advanced Industrial Countries (Cornell University Press). 


\section{NORMAS CITADAS}

Decreto con Fuerza de Ley $N^{\circ}$ 4/20.018 que fija el texto refundido, coordinado y sistematizado del Decreto con Fuerza de Ley $N^{\circ}$ 1, del Ministerio de Minería, de 1982, Ley General de Servicios Eléctricos en materia de Energía Eléctrica.

Decreto con Fuerza de Ley $\mathrm{N}^{\circ}$ 1/19.653 que fija el texto refundido, coordinado y sistematizado de la Ley $\mathrm{N}^{\circ}$ 18.575, Orgánica Constitucional de Bases Generales de la Administración del Estado, del Ministerio Secretaría General de la Presidencia, publicado en el D.O. de 17 de noviembre de 2001.

Ley $\mathrm{N}^{\circ}$ 18.410, del 22 de mayo de 1985, que crea la Superintendencia de Electricidad y Combustibles.

Ley $\mathrm{N}^{\circ}$ 19.940, del 13 de marzo de 2004, que regula sistemas de transporte de energía eléctrica, establece un nuevo régimen de tarifas para sistemas eléctricos medianos e introduce las adecuaciones que indica a la Ley General de Servicios Eléctricos.

Ley $\mathrm{N}^{\circ}$ 20.018, del 19 de mayo de 2005, que modifica el marco normativo del sector eléctrico. Ley $N^{\circ} 20.402$, del 3 de diciembre de 2009, que crea el Ministerio de Energía, estableciendo modificaciones al Decreto Ley $\mathrm{N}^{\circ} 2.224$, de 1978 y a otros cuerpos legales.

Decreto Ley 2.224 de 1978, publicado en el D.O. el 8 de julio de 1978, que crea la Comisión Nacional de Energía.

Decreto No 6 de 1985, del Ministerio de Minería, publicado en el D.O. el 28 de febrero de 1985, que aprueba el reglamento de coordinación de la operación interconectada de centrales generadoras y líneas de transporte.

Decreto Supremo No 327 de 1997, del Ministerio de Minería, publicado en el D.O. el 10 de septiembre de 1998, que fija el reglamento de la Ley General de Servicios Eléctricos.

Decreto Supremo No 291 de 2007, del Ministerio de Economía, Fomento y Reconstrucción, publicado en el D.O. el 4 de agosto de 2008, que aprueba el reglamento que establece la estructura, funcionamiento y financiamiento de los Centros de Despacho Económico de Carga.

Decreto $N^{\circ} 130$ de 2011, del Ministerio de Energía, publicado en el D.O. con fecha 31 de diciembre de 2012, que aprueba reglamento que establece las disposiciones aplicables a los servicios complementarios con que deberá contar cada sistema eléctrico para la coordinación de la operación del sistema en los términos a que se refiere el artículo $137^{\circ}$ de la Ley General de Servicios Eléctricos.

Decreto $N^{\circ} 115$ de 2012, del Ministerio de Energía, publicado en el D.O. el 5 de agosto de 2013, que modifica el Decreto Supremo No 291, de 2007, del Ministerio de Economía, Fomento y Reconstrucción, que aprueba el reglamento que establece la estructura, funcionamiento y financiamiento de los Centros de Despacho Económico de Carga.

\section{JURISPRUDENCIA CITADA}

Dictamen $N^{\circ} 70.637$, de 30 de octubre de 2013, de la Contraloría General de la República Resolución Exenta $N^{\circ} 1121$, de 30 de junio de 2005, que aplicó sanciones a Empresa Eléctrica Guacolda, por transgresiones a la normativa vigente; disponible en <http://www. sec.cl/sitioweb/electricidad_sanciones/RE_1121.pdf> 
